\title{
La celebración de consultas populares locales a petición de los vecinos
}

\author{
María Jesús García García
}

\begin{abstract}
Sumario: I. La formulación del principio constitucional de participación de los ciudadanos y las consultas populares. - II. Participación democrática y consultas populares: 1. El derecho fundamental a participar en los asuntos públicos y las consultas populares; 2. Las consultas populares como manifestación de la democracia participativa.-III. Delimitación de competencias sobre las consultas populares. -IV. La configuración legal de las consultas populares. -V. La naturaleza jurídica de las consultas populares promovidas a iniciativa vecinal: 1 . La solicitud de consultas populares como derecho subjetivo de los vecinos; 2. Distinción del derecho de petición. -VI. El ámbito subjetivo de las consultas populares: 1 . El ejercicio del derecho de petición de consultas populares: 2. Legitimación para participar en la consulta.-VII. EI objeto de las consultas populares y sus requisitos: 1. El objeto de las consultas populares: requisitos materiales y competenciales; 2 . El objeto de las consultas populares desde un punto de vista formal. -VIII. El procedimiento de las consultas populares: 1. Los acuerdos de la Administración local sobre iniciación y celebración de la consulta popular; 2. La autorización del Gobierno como requisito de validez de la consulta; 3 . Convocatoria de la consulta y celebración de la misma. -IX. Los efectos de la consulta popular.
\end{abstract}

Laburpena. Hitz gakoak.-Resumen. Palabras clave.-Abstract. Key words.

\section{La formulación del principio constitucional de participación de los ciudadanos y las consultas populares}

La Constitución promueve la participación de los ciudadanos en los asuntos públicos a lo largo de su articulado. Así el artículo 9.2 de la Constitución recoge el deber de los poderes públicos de facilitar la participación 
de todos los ciudadanos en la vida política, económica, cultural y social. La participación ciudadana queda elevada a la categoría de principio constitucional (1).

Posteriormente este principio proyecta su influencia sobre los distintos ámbitos de actuación pública, tanto a nivel legislativo como administrativo y judicial, de forma que todos los ámbitos funcionales de lo público tienen reconocida en el texto constitucional una forma de participación ciudadana.

En el ámbito legislativo, el artículo 87 de la Constitución remite a una ley orgánica la regulación de las formas de ejercicio y de los requisitos de la iniciativa legislativa popular, e igualmente en el ámbito judicial el artículo 125 reconoce la participación de los ciudadanos en la Administración de Justicia a través de la institución del Jurado.

Pero la participación de los ciudadanos en los asuntos públicos se manifiesta especialmente y se hace más patente en el ámbito de actuación del gobierno y administración (2). Así por ejemplo, el procedimiento de elaboración de disposiciones reglamentarias, en relación al cual el artículo 105 de la Constitución garantiza la audiencia de los ciudadanos.

Además de estos preceptos, la Constitución está salpicada de referencias a otras manifestaciones de la participación ciudadana. El artículo 48 establece la obligación de los poderes públicos de promover las condiciones para la participación de la juventud en el desarrollo político, social, económico y cultural. El artículo 27.5 y 7 alude a la participación en la programación de la enseñanza y en el control y gestión de los centros públicos. El artículo 129.1 remite a la ley el establecimiento de formas de participación de los interesados en la Seguridad Social y en la actividad de determinados organismos públicos. Otros artículos, como el 51.2 se refieren a las organizaciones de consumidores y usuarios y a la audiencia a las mismas en las cuestiones que puedan afectarles remitiendo a las determinaciones legales posteriores. El artículo 52 referido a las organizaciones profesionales implica también una cierta participación en los asuntos públicos al encomendarles la defensa de los intereses económicos que les son propios. Por su parte, el artículo 31 se refiere a la planificación de la actividad económica tomando en consideración el asesoramiento y colaboración de los sindicatos y otras organizaciones profesionales, empresariales y económicas.

El texto constitucional sin embargo no agota ni mucho menos las distintas formas de participación ciudadana en la actuación administrativa,

(1) SÁNCHEZ MORÓN, M. «El principio de participación en la Constitución española», Revista de Administración Pública, N. ${ }^{\circ}$ 89, 1979, Pág. 171 y ss. Véase también GARCÍA DE ENTERRÍA, E. «Principios y modalidades de la participación ciudadana en la vida administrativa», en el libro homenaje al Profesor Villar Palasí, coord. GÓMEZ-FERRER MORANT, R., 1989, pag. 437 y ss. SÁNCHEZ BLANCO, A. «La participación como coadyuvante del Estado social y democrático de derecho", RAP N. ${ }^{\circ} 111,1986$.

(2) Vid SÁNCHEZ MORÓN, M: La participación del ciudadano en la Administración Pública, Centro de Estudios Constitucionales, 1980. 
pues la formulación del principio de participación en su artículo 9.2 ha dado pie a la configuración legislativa de formas de participación que aunque no están expresamente previstas en el texto constitucional, si resultan directamente de sus directrices y principios.

Un buen ejemplo de estas afirmaciones es el ámbito de la Administración local, en cuanto cauce inmediato de participación ciudadana en los asuntos públicos, donde se han instaurado formas de participación ciertamente novedosas, como puedan ser la iniciativa ciudadana para presentar proyectos de actuaciones, decisiones y normas y las consultas populares que constituyen un mecanismo a través del cual los vecinos, previo cumplimiento de los requisitos y cauces procedimentales fijados por la ley, pueden manifestar su opinión sobre un determinado asunto de relevancia local, sin que el resultado de esta consulta vincule a los órganos que deben decidir. Se trata de un instrumento de conocimiento de la opinión de los vecinos sobre asuntos de la competencia propia municipal que combinada con la iniciativa popular da lugar a una figura nueva y exclusiva del ámbito local como son las consultas populares a iniciativa vecinal.

\section{Participación democrática y consultas populares}

La participación democrática de los ciudadanos en los asuntos públicos puede revestir distintas manifestaciones y todas ellas encuentran acomodo de forma más o menos explícita en el texto constitucional. Es cierto que la Constitución se decanta por un modelo de democracia representativa en donde la soberanía y el ejercicio de las potestades públicas se ejerce por representantes libremente elegidos por el pueblo a través de sufragio universal, libre, igual, directo y secreto. Pero no es menos cierto que la Constitución permite instituir otras formas de democracia que coexisten aunque con menor protagonismo con la democracia representativa y la complementan (3). Me refiero a la democracia directa y a la democracia participativa. Se trata por tanto de determinar en cual de estas dos manifestaciones democráticas se inscriben la consultas populares (4).

(3) Sobre la necesidad de complementar los mecanismos de la democracia representativa con las formas de la democracia participativa puede verse MUÑOZ MACHADO, S. "Las concepciones del Derecho Administrativo y la idea de participación en la Administración", RAP N. ${ }^{\circ} 84,1977$, pág.519-536. Igualmente SÁNCHEZ MORÓN, M. "Crónica de unas jornadas sobre gobernabilidad y participación en la Administración local", Revista Vasca de Administración Pública N. ${ }^{\circ} 49,1997$, Pág. 376.

(4) Ver RODRÍGUEZ, A. "Consultas populares», en el libro Reformas estatutarias y distribución de competencias coord. por BALAGUER CALLEJÓN, F., ORTEGA ALVAREZ, L., CÁMARA VILLAR, G., MONTILLA MARTOS, J.A., 2007. 


\section{El derecho fundamental a participar en los asuntos públicos y las consultas populares}

El artículo 23 de la Constitución eleva a la categoría de derecho fundamental la participación de los ciudadanos en los asuntos públicos, directamente o por medio de representantes. La redacción de este precepto y la ambigüedad de la expresión "asuntos públicos» ha dado lugar a distintas interpretaciones acerca del alcance omnicomprensivo de este artículo y la posibilidad de que por esta vía quedara configurado un derecho constitucional a la participación de los ciudadanos en cualesquiera parcelas o ámbitos públicos (5), posición que la jurisprudencia del Tribunal Constitucional ha venido a reconducir a sus justos términos.

Según la sentencia del Tribunal Constitucional 119/95 de 17 de julio, el artículo 23 garantiza un derecho de participación que puede ejercerse directamente o a través de representantes y que supone el ejercicio de poder político. Sólo allí donde la llamada a la participación comporte el ejercicio directo o por medio de representantes del poder político, esto es, sólo allí donde se llame al pueblo como titular de ese poder, estaremos en el marco del artículo 23.1 y podrá aducirse el derecho fundamental aludido (6).

El Tribunal Constitucional reconoce por tanto dos formas de democracia que se acomodan en el ámbito del artículo 23 de la Constitución: la representativa y la directa. Esta última se manifiesta en aquellos ca-

(5) A favor de la inclusión en el ámbito del artículo 23 de la CE de la participación administrativa se han pronunciado autores como PÉREZ MORENO, "Crisis de la participación administrativa», RAP N. ${ }^{\circ} 199,1989$, Pág. 107 y ss. Igualmente SANTAMARÍA PASTOR, Comentarios a la Constitución, dirigidos por GARRIDO FALLA, F., Civitas, 1985, Pág. 445, y SÁNCHEZ BLANCO, en el volumen colectivo La Participación, Anuari de la Facultad de Dret, Estudi General de Lleida, Barcelona, 1985, Pág. 253.

En esta misma línea critica con la interpretación dada al artículo 23 por el Tribunal Constitucional, cabe citar también a JORDANA FRAGA, J., "Derecho a la participación, participación administrativa y Medio Ambiente", Revista Andaluza de Administración Pública, N. ${ }^{\circ} 11,1992$, Pág. 99 y ss. y ALZAGA VILLAMIL, Comentario sistemático a la Constitución española de 1978, Ediciones del Foro, Madrid, 1978, Pág. 235.

(6) "Este entendimiento de la expresión "participar en los asuntos públicos», que hasta ahora hemos examinado desde la perspectiva del derecho de participación a través de representantes, es perfectamente trasladable (o más bien habría que afirmar que debe ser trasladado, puesto que nos movemos dentro del mismo precepto y no parece conveniente otorgar a una única expresión dos sentidos distintos) a la participación directa a la que igualmente se refiere el artículo 23.1 CE. Aunque han sido menos las ocasiones en que este Tribunal ha tenido oportunidad de pronunciarse al respecto, en ellas ha afirmado que "la participación directa que en los asuntos públicos ha de corresponder a los ciudadanos es la que se alcanza a través de las consultas populares previstas en la propia Constitución (artículos 92, 149.1.32, 151.1, 152.2, 167.3 y 168.3) (STC 63/1987, fundamento jurídico $5 .^{\circ}$ y ATC 399/1990, fundamento jurídico 2.\%. Todos los preceptos enumerados se refieren a distintas modalidades de referéndum y, en última instancia, a lo que tradicionalmente se vienen considerando como formas de democracia directa, es decir, a aquellos supuestos en los que la toma de decisiones políticas se realiza mediante un llamamiento directo al titular de la soberanía. Dentro de ellas habría que encuadrar también el denominado régimen de concejo abierto al que se refiere el artículo 140 CE y, asimismo, este Tribunal ha vinculado con el artículo 23.1 CE la iniciativa legislativa popular que establece el artículo 87.3 CE (STC 76/1994 [ RTC 1994|76] y AATC 570/1989 y 140/1992)" 
sos en los que el llamamiento al titular de la soberanía se produce sin intermediación alguna de partidos o representantes. Quedarían integradas dentro de esta forma de democracia directa la iniciativa legislativa popular del artículo 87.3 de la Constitución, las formas de organización basadas en el concejo abierto y a las distintas modalidades de referéndum previstas en la Constitución.

El artículo 149.1.32 de la Constitución atribuye al Estado la competencia para autorizar la celebración de consultas populares por vía de referéndum. Igualmente, la Ley Orgánica $2 / 80$ de 18 de enero, reguladora de las distintas modalidades de referéndum establece en su artículo 2.2 que la autorización será acordada por el Gobierno, a propuesta de su Presidente, salvo en el caso en que este reservada por la Constitución al Congreso de los Diputados.

Precisamente la necesidad de autorización de las consultas populares locales por el Gobierno de la Nación establecida en el artículo 71 de la $L R B R L$, y la regulación efectuada por algunas normas autonómicas que vinculan la participación en las consultas populares con el derecho de sufragio activo en los términos de la legislación de régimen electoral general, así como el cauce previsto para el ejercicio de las mismas a través de un procedimiento similar al regulado en la Ley Orgánica de Régimen Electoral General con intervención de la Administración electoral (7) han generado dudas sobre la verdadera naturaleza jurídica de dichas consultas (8), y sobre la posibilidad de que pudieran constituir una modalidad de referéndum, en concreto una concreción del artículo 92 de la Constitución (9) en el ámbito local (10). Las consecuencias jurídicas de esta posibilidad no son intrascendentes, pues ello llevaría a incluirlas en el ámbito de aplicación

(7) El artículo 11 de la Ley Foral 27/2002 de 28 de noviembre de 2006 reguladora de las consultas populares de ámbito local remite a la Ley Orgánica de Régimen Electoral General con las particularidades que se recogen en esta Ley Foral.

(8) En este sentido ha destacado PEMÁN GAVÍN, J.M., que no pocas de las fórmulas de participación ciudadana que regula la normativa local están vinculadas a mecanismos electorales o de representación, lo que en su opinión pone en cuestión al menos en el ámbito local la distinción que en ocasiones se hace entre democracia representativa y democracia directa. «El nuevo impulso a las fórmulas de participación ciudadana en la Administración local», Revista Aragonesa de Administración Pública N. ${ }^{\circ} 27,2005$, Pág. 50, n.p.p 73.

(9) Sobre esta cuestión puede verse LÓPEZ GONZÁLEZ, J.L., «El referéndum nacional consultivo sobre decisiones políticas de especial trascendencia", Cuadernos constitucionales de la Cátedra Fradrique Furió, N. ${ }^{\circ}$ 38/39, Valencia, 2002. Puede verse también RODRíGUEZ ZAPATERO, J.L. «EI referéndum consultivo del artículo 92 de la Constitución española de 1978: un análisis crítico", Diario La Ley, 1986, Tomo 1, Pág. 1156. Centrado específicamente en el ámbito de la Administración local puede verse también IBÁÑEZ MACÍAS, A. El referéndum local en España: régimen jurídico, Servicio de publicaciones de la Universidad de Cádiz, 2005.

(10) Ha sido muy frecuente la invocación ante los Tribunales del artículo 23 de la Constitución y su supuesta vulneración cuando se han planteado recursos con ocasión de la petición de celebración de consultas populares. 
del artículo 23 de la Constitución y a calificarlas como una forma de democracia directa.

Tanto razones de fondo como de forma se oponen a esta conclusión.

En este sentido es relevante la reciente STC 103/2008 de 11 de septiembre (11) que define lo que constitucionalmente debe ser considerado como referéndum (12). El Tribunal Constitucional configura y delimita el concepto de referéndum, estableciendo las notas que lo definen, lo que nos permite contrastarlo con las consultas populares locales, a efectos de determinar si concurren en éstas los requisitos del referéndum.

De acuerdo con la mencionada sentencia el referéndum constituye una apelación al cuerpo electoral como titular de la soberanía, que tiene por objeto conocer su parecer sobre un determinado asunto, manifestado a través de un procedimiento electoral, y que implica el ejercicio de poder político, de forma que la opinión así manifestada constituirá una manifestación de la voluntad popular. La finalidad del Ilamamiento es por tanto el ejercicio del poder político, manifestado normalmente a través de representantes, pero que en este caso se ejerce directamente por los ciudadanos (13).

Ninguna de estas notas confluyen en las consultas populares de ámbito local.

En primer lugar las competencias de las Administraciones locales se expresan sobre todo a través de actos de naturaleza administrativa y no

(11) Resuelve el recurso de inconstitucionalidad n. ${ }^{\circ} 5707 / 2008$, interpuesto por el Presidente del Gobierno contra la Ley del Parlamento Vasco 9/2008, de 27 de junio, «de convocatoria y regulación de una consulta popular al objeto de recabar la opinión ciudadana en la Comunidad Autónoma del País Vasco sobre la apertura de un proceso de negociación para alcanzar la paz y la normalización política».

(12) Según la citada sentencia, "el referéndum es un instrumento de participación directa de los ciudadanos en los asuntos públicos, esto es, para el ejercicio del derecho fundamental reconocido en el artículo 23.1 de la Constitución. No es cauce para la instrumentación de cualquier derecho de participación, sino específicamente para el ejercicio del derecho de participación política, es decir de aquella participación que normalmente se ejerce a través de representantes y que excepcionalmente pude ser directamente ejercida por el pueblo». (...) «El referéndum es, por tanto, una especie del género consulta popular con la que no se recaba la opinión de cualquier colectivo sobre cualesquiera asuntos de interés público a través de cualesquiera procedimientos, sino aquella consulta cuyo objeto se refiere estrictamente al parecer del cuerpo electoral expresivo de la voluntad del pueblo (STC 12/2008 de 29 de enero), conformado y exteriorizado a través de un procedimiento electoral, esto es, basado en el censo, gestionado por la Administración electoral y asegurado con garantías jurisdiccionales específicas, siempre en relación con los asuntos públicos cuya gestión, directa o indirecta, mediante el ejercicio del poder político por parte de los ciudadanos constituye el objeto del derecho fundamental reconocido por la Constitución en el artículo 23. Para calificar una consulta como referéndum o, más precisamente, para determinar si una consulta se verifica por vía de referéndum y su convocatoria requiere entonces de una autorización reservada al Estado, ha de atenderse a la identidad del sujeto consultado, de manera que siempre que éste sea el cuerpo electoral, cuya vía de manifestación propia es la de los distintos procedimientos electorales, con sus correspondientes garantías, estaremos ante una consulta referendaria».

(13) Señala igualmente el Tribunal Constitucional que el carácter vinculante o no de su resultado no es determinante para atribuir a una consulta el carácter de referéndum. 
política, de forma que la opinión o parecer de los ciudadanos se proyecta sobre cuestiones de carácter administrativo y no político (14). La función de gobierno de que se habla en los artículos 140 y 141 de la Constitución se traduce fundamentalmente en actuaciones jurídico- administrativas (15) en tanto en cuanto manifestación del ejercicio de competencia conferidas por el legislador estatal o autonómico. Es cierto que en la mayoría de las ocasiones las decisiones administrativas van precedidas o acompañadas por una opción de carácter político que sin embargo no siempre es posible aislar de la actuación administrativa. Existe cierta dificultad en el contexto de la Administración local para deslindar las decisiones de carácter político de las decisiones jurídico-administrativas que suponen el ejercicio de competencias atribuidas por el legislador estatal o autonómico (16).

En este sentido la jurisprudencia señala que las decisiones de ámbito local han de encontrar una habilitación que puede encontrase en las competencias municipales nominadas en la Ley de Bases de Régimen Local, en la legislación sectorial o en la propia cláusula de la autonomía municipal (17). En base a ese principio de autonomía local se ha sustentado la posibilidad de la existencia de actos políticos de carácter local que no suponen ejecución o cumplimiento de normas estatales o autonómicas (18). Sin entrar ahora en esta cuestión, es evidente que las decisiones locales revisten fundamentalmente carácter administrativo (con independencia de que previa o simultáneamente a su adopción se haya efectuado una opción política adoptada autónomamente por la Administración local), y que

(14) La Sentencia delTribunal Superior de Justicia de la Comunidad Foral de Navarra de 11 de octubre de 2002 pone de manifiesto que el ámbito del artículo 92 de la Constitución se refiere a las decisiones políticas de especial trascendencia y ello resulta difícil de adaptar al ámbito de la gestión competencial reservada a los municipios, que es más de índole administrativa que política.

(15) En este sentido puede citarse MARTíNEZ LÓPEZ-MÚÑIZ, J.L., "Actos de gobierno y Administración local», en el libro homenaje al Prf. J.M Boquera Oliver, Nuevas perspectivas del Régimen local, Tirant lo Blanch, Valencia, 1999, pág. 653. En opinión del citado autor "...la función de gobierno sólo podrá traducirse para producir algún efecto jurídico, en actuaciones jurídicamente administrativas».

(16) Sobre este punto puede citarse la opinión de SÁNCHEZ MORÓN, M. El sistema político local: fórmulas de gobierno y participación ciudadana, Informe sobre Gobierno Local, MAP, 1992, Pág. 294. El citado autor señala que las competencias de las corporaciones locales son de orden administrativo exclusivamente, pero se ejercen de acuerdo con los criterios políticos que autónomamente se fijan las propias corporaciones. En este sentido, las entidades locales tienen naturaleza política, o si se prefiere, político-administrativa.

(17) Ver la STS de 17 de julio de 1998 referente a una decisión municipal por la que se declararaba a un sujeto como persona non grata.

(18) Sobre la existencia de actos políticos en el ámbito de la Administración local puede verse BARATA I MIR, J. Los actos de gobierno en el ámbito municipal,Tecnos, 1999, que sin negar la prevalencia de las manifestaciones administrativas, no descarta sin embargo la posibilidad de ciertos actos de carácter político, en donde la decisión municipal no obedece a la ejecución o cumplimiento de normas estatales o autonómicas. Ver también GARRIDO CUENCA, N. El acto de gobierno: un análisis en los ordenamientos francés y español, CEDES, 1998. 
las manifestaciones políticas, caso de admitirse se reducen a supuestos muy limitados (19).

De ello cabe concluir que las consultas populares son una modalidad de participación administrativa y no política, razón por la cual está ausente en ellas el llamamiento al cuerpo electoral en cuanto titular de la soberanía. El artículo 71 de la Ley de Bases de régimen local no concreta cuales sean los sujetos Ilamados a participar en la consulta, simplemente alude a los asuntos de carácter local que sean de especial relevancia para los intereses de los vecinos, razón por la cual el ámbito subjetivo de la consulta bien podría referirse precisamente a este colectivo. Es cierto que algunas Comunidades Autónomas, exigen para participar en la consulta popular que los vecinos ostenten el derecho de sufragio activo (20) en las elecciones municipales pero ese llamamiento no se hace como titulares de la soberanía, sino en su condición de vecinos. El derecho a participar en la consulta popular viene dado por ostentar la condición de vecino, aunque a ello se añadan en ocasiones otros requisitos adicionales. En cambio otras normas autonómicas son más permisivas reconociendo este derecho a los vecinos mayores de edad que estén inscritos en el padrón municipal (21).

En todo caso la LRBRL no contiene la exigencia del derecho de sufragio activo, y las consultas populares no expresan la voluntad del cuerpo electoral, sino opiniones colectivas pero no generales. Dichas consultas no implican ejercicio de poder político ni expresión de la voluntad popular. En este sentido no cabe confundir soberanía con autonomía local. La convocatoria y celebración de consultas populares es una manifestación de la autonomía local, pero esta no puede confundirse con la independencia o soberanía.

Pero además de estos argumentos, también desde un punto de vista formal queda acreditado que las consultas populares no son una modalidad de referéndum, ni tampoco una manifestación de democracia directa. En primer lugar, porque tal y como ha señalado la STC 103/2008 de 11 de septiembre y el Dictamen del Consejo de Estado 1119/2008, de 3 de julio, los mecanismos de la democracia directa quedan limitados a aquellos expresamente previstos en la Constitución, sin que quepa la posibilidad de su ampliación ni siquiera por ley (22). En este sentido es evidente que la

(19) En este contexto se han querido situar los acuerdos plenarios en virtud de los cuales se solicita al Gobierno de la Nación la correspondiente autorización para la celebración de un referéndum popular. Así por ejemplo BARATA I MIR, Los actos de gobierno en el ámbito municipal, obra cit. pág.194.

(20) Así por ejemplo la Ley 2/2001 de 3 de mayo sobre consultas populares en Andalucía.

(21) Así la Ley Foral 27/2002 de 28 de octubre.

(22) Según el Dictamen del Consejo de Estado la Constitución regula distintas modalidades de referéndum. Así el previsto en el artículo 92 sobre decisiones políticas de especial trascendencia, los previstos en los artículos 151 y 152 en relación con los procedimientos de aprobación o de reforma de los Estatutos de Autonomía, y los de reforma constitucional contenidos en los artículos 167.3 y 168 de la Constitución, así como el previsto en la disposición transitoria cuarta. 
Constitución establece distintas modalidades de referéndum entre las que no se encuentran las consultas populares. Y en segundo lugar porque atendiendo a lo dispuesto por el artículo 92.3 de la Constitución es necesaria una ley orgánica para regular las condiciones y el procedimiento de las distintas modalidades de referéndum previstas en la Constitución. Debe tenerse en cuenta que la regulación del derecho de referéndum está sujeta a ley orgánica de forma específica, por el artículo 92.3 de la Constitución y de forma genérica por tratarse de un derecho fundamental.

Sin embargo, la Ley Orgánica 2/1980 reguladora de las distintas modalidades de referéndum excluye expresamente de su regulación a las consultas populares de ámbito local, remitiendo a lo dispuesto en la legislación de régimen local, que carece del carácter de Ley Orgánica. La regulación de las consultas populares en la Ley de Bases de Régimen Local y en la legislación autonómica de desarrollo permite concluir sin ningún género de dudas que dichas consultas no constituyen un mecanismo de la democracia directa, y por tanto no están incluidas en el artículo 23 de la Constitución, ni constituyen una modalidad de referéndum ceñida al ámbito local.

Así pues, si las consultas populares no constituyen una modalidad de referéndum, y por lo tanto no pueden entenderse afectadas por el artículo 149.1.32 de la Constitución que atribuye al Estado competencia exclusiva para autorizar la celebración de consultas populares por vía de referéndum, ¿cual es la razón por la que su convocatoria está sujeta a la previa autorización del Gobierno? Esta cuestión ha de analizarse teniendo en cuenta que el régimen jurídico de las consultas populares forma parte de la legislación básica de régimen local. Así pues, la necesidad de autorización por parte del Gobierno tiene su base en el artículo 149.1.18 del Constitución, y en las competencias del Estado para establecer las bases del régimen jurídico de las Administraciones públicas que son las que imponen esta exigencia.

\section{Las consultas populares como manifestación de la democracia participativa}

La conclusión anterior fuerza a considerar las consultas populares de ámbito local como una forma de democracia participativa que no significa ni presupone el ejercicio de la soberanía popular, sino que otorga a los ciudadanos la posibilidad de proporcionar a los poderes públicos (Administración), elementos de juicio suficientes para garantizar el acierto y oportunidad de las decisiones administrativas (23) y revestirlas además

(23) Señala GARCÍA DE ENTERRÍA que la participación ciudadana en el funcionamiento de la Administración halla su justificación en el ámbito de la discrecionalidad, donde lo que interesa es precisar 
de legitimidad democrática. Es evidente que las consultas populares de ámbito local se inscriben en este tertium genus, ya que si bien suponen una participación directa en los asuntos públicos, sin embargo no implican el ejercicio de poder político ni una manifestación de la soberanía popular, sino más bien una participación administrativa propiciada por el hecho de que el ámbito en el que se plantean las consultas populares locales es el de las competencias municipales, de índole más administrativa que política (24).

Y a diferencia de las manifestaciones de la democracia directa que han de estar expresamente previstas en la Constitución, las formas de democracia participativa pueden ser previstas por el legislador sin necesidad de reconocimiento constitucional expreso. Las manifestaciones de la democracia participativa no son totalmente desconocidas para el legislador. Así la audiencia e información pública en el procedimiento de elaboración de disposiciones administrativas son manifestaciones de una participación funcional en el procedimiento administrativo que se concretan en los tramites de audiencia e información pública y que gozan de una cierta tradición en nuestro derecho además de un reconocimiento constitucional expreso en el artículo 105 de la CE. Pero no es suficiente con reconocer la participación de los ciudadanos en la adopción de actos y disposiciones públicas promovidas por la Administración, sino que hay que dar un paso más y reconocerles el derecho a ejercer la iniciativa para proponer a la Administración actuaciones, decisiones e incluso proyectos normativos (25). Y esta iniciativa puede conllevar incluso la capacidad para apreciar la relevancia del asunto que se somete a la consideración de la Administración y la conveniencia de someterla a consulta popular.

Las consultas populares de ámbito local son una llamada a conocer la opinión de los vecinos sobre un asunto, y se configuran como una ma-

\footnotetext{
lo "oportuno" frente a lo «inoportuno". Para el citado autor la oportunidad de la decisión depende no de su perfección técnica sino de su adecuación a las demandas sociales y a su aceptación por el cuerpo social, cuya opinión resulta investigada a través las técnicas participativas. "La participación del administrado en las funciones administrativas", Revista de Seguridad Social N. ${ }^{\circ} 4,1979$, pág. 11-23.

(24) Se trata de una participación en la actuación administrativa - prevista ya, por cierto, en la legislación anterior a la Constitución-, que no es tanto una manifestación del ejercicio de la soberanía popular cuanto uno de los cauces de los que en un Estado social deben disponer los ciudadanos - bien individualmente, bien a través de asociaciones u otro tipo de entidades especialmente aptas para la defensa de los denominados intereses "difusos» - para que su voz pueda ser oída en la adopción de las decisiones que les afectan. Dicho derecho, cuya relevancia no puede ser discutida, nace, sin embargo, de la Ley y tiene - con los límites a que antes hemos aludido - la configuración que el legislador quiera darle; no supone, en todo caso, una participación política en sentido estricto, sino una participación -en modo alguno desdeñable - en la actuación administrativa, de carácter funcional o procedimental, que garantiza tanto la corrección del procedimiento cuanto los derechos e intereses legítimos de los ciudadanos.
}

(25) GARCíA GARCÍA, M.J., "La participación ciudadana en la elaboración de disposiciones reglamentarias: participación funcional e iniciativa reglamentaria», Revista catalana de Derecho Político, n. ${ }^{\circ} 37,2008$, págs. $417-460$. 
nifestación democrática de su opinión o parecer. De ahí que las normas autonómicas hayan previsto que la consulta popular deba decidirse por procedimientos democráticos que remiten a procedimientos electorales basados en el sufragio universal, libre, igual, directo y secreto (26).

No obstante, al no constituir una manifestación de la democracia directa, no presupone el ejercicio de la soberanía ni del poder político, razón por la cual no es determinante para su ejercicio ostentar el derecho de sufragio activo en los términos previstos en la legislación electoral, y por ende son perfectamente legítimas también aquellas opciones autonómicas que atribuyen el derecho a participar en la consulta popular a todos los vecinos mayores de edad, con independencia de que ostenten o no derecho de sufragio activo para participar en las elecciones municipales, ya que no se trata de un derecho de carácter político.

Así pues, ni el derecho a promover la celebración de consultas populares, ni tampoco el derecho a participar en las mismas pueden considerarse incluidos en el ámbito del artículo 23 de la Constitución como una manifestación del derecho fundamental a participar en los asuntos públicos, y no gozan por ende de los mecanismos de tutela que les son propios a los derechos fundamentales (27).

Las formas de la democracia participativa implican la colaboración de los ciudadanos con los poderes públicos especialmente en aquellos ámbitos de mayor discrecionalidad administrativa, pero sin sustituir en ningún momento la capacidad de decisión de los órganos competentes, sino simplemente como un complemento de su actuación, tal y como así ocurre con las consultas populares.

Se trata en definitiva de complementar la democracia representativa con los mecanismos de la democracia participativa, y ello por varias razones. En primer lugar porque no puede negarse que actualmente existe un progresivo desinterés por parte de los ciudadanos en los asuntos públicos, así como un cierto descrédito de los poderes públicos, motivado quizá por la falta de acercamiento o sintonía entre la esfera pública y los verdaderos intereses e inquietudes de la ciudadanía. De ahí la necesidad no sólo de

(26) Artículo 3 de la Ley que regula las consultas populares locales en Andalucía.

(27) Según la citada sentencia 119/1995 del Tribunal Constitucional «Fuera del artículo 23 de la Constitución quedan cualesquiera otros títulos de participación que, configurados como derechos subjetivos o de otro modo, puedan crearse en el ordenamiento, pues no todo derecho de participación es un derecho fundamental. Para que la participación regulada en una Ley pueda considerase como una concreta manifestación del artículo 23 de la Constitución es necesario que se trate de una participación política, es decir, de una manifestación de la soberanía popular, que normalmente se ejerce a través de representantes y que excepcionalmente, puede ser directamente ejercida por el pueblo, lo que permite concluir que tales derechos se circunscriben al ámbito de la legitimación democrática directa del Estado y de las distintas entidades territoriales que lo integran, quedando fuera otros títulos participativos que derivan, bien de otros derechos fundamentales, bien de normas constitucionales de otra naturaleza, o bien, finalmente, de su reconocimiento legislativo". 
respetar los mecanismos de la democracia participativa ya establecidos, sino también de ampliarlos, reconociendo incluso la iniciativa para presentar a los poderes públicos propuestas de actuaciones o decisiones e incluso proyectos de carácter normativo.

La celebración de consultas populares, e incluso el reconocimiento de la iniciativa para promoverlas a los ciudadanos acentúan igualmente el acercamiento de los ciudadanos a las instituciones. En este sentido la Administración se revela como la instancia pública más accesible y cercana a los ciudadanos y se configura como cauce instrumental de comunicación con el ciudadano. Surge así la nueva Administración relacional propiciada por las nuevas tecnologías como soporte al derecho de información del ciudadano y como instrumento para el intercambio de información.

\section{Delimitación de competencias sobre las consultas populares}

Excluida la consideración de las consultas populares locales como una modalidad de referéndum, cabe señalar que el título competencial que delimita las competencias en esta materia viene constituido por el artículo 149.1.18 de la Constitución que atribuye al Estado la competencia para establecer las bases de régimen jurídico de las Administraciones públicas.

Según esta distribución de competencias, el régimen básico de las consultas populares forma parte de la legislación básica de régimen local, correspondiendo a las Comunidades Autónomas el desarrollo de esta materia. No obstante, algunos Estatutos de Autonomía han asumido su regulación en atención a un título competencial específico sobre consultas populares totalmente innecesario si tenemos en cuenta que su posibilidad de intervención en esta materia arranca de la delimitación de competencias efectuada por el artículo 149.1 .18 (28) y de lo previsto por la LRBR (29). Así por ejemplo el Estatuto de Autonomía de Aragón (30)

\footnotetext{
(28) En este sentido la variedad de fórmulas de los Estatutos de Autonomía a la hora de asumir competencias en esta materia es muy amplia y no siempre acertada. Así por ejemplo el Estatuto de Autonomía de Andalucía señala que corresponde a la Comunidad Autónoma el desarrollo legislativo del sistema de consultas populares locales, de conformidad con lo que dispongan las Leyes a que se refiere el apartado 3 del artículo 92 y el número 1 y 32 del artículo 149.1 de la Constitución, correspondiendo al Estado la autorización de su convocatoria. Otros estatutos omiten la calificación local o municipal de las consultas y señalan que su regulación se efectuará por las comunidades autonomas de conformidad con lo que disponga la Ley a que se refiere el artículo 92.3 de la Constitución y demás leyes del Estado, reconociendo también que corresponde al Estado la autorización de su convocatoria. Así por ejemplo el Estatuto de Autonomía de la Rioja.
}

(29) Vid FONT I LLOVET, T. «El referéndum local en España», Autonomies, N. ${ }^{\circ}$ 2-3, 1985, Pág. 127 que pone de manifiesto que es totalmente innecesario que los Estatutos contengan una referencia expresa a la materia "consultas populares", siendo suficiente que la comunidad Autónoma ostente competencias en la materia de régimen local para poder legislar sobre el referéndum municipal.

(30) Ver el artículo 71 de la Ley Orgánica 5/2007 de 20 de abril de Reforma del Estatuto de Autonomía de Aragón. 
reconoce competencia exclusiva para el establecimiento del régimen jurídico, las modalidades, el procedimiento, la realización y la convocatoria por la Comunidad Autónoma o por los entes locales en el ámbito de sus competencias de encuestas, audiencias públicas, foros de participación y cualquier otro instrumento de consulta popular, con excepción de la regulación del referéndum y de lo previsto en el artículo 149.1.32 de la Constitución. En un sentido muy similar pueden verse el Estatutos de autonomía de Cataluña (31).

Otras Comunidades Autónomas asumen competencias de desarrollo legislativo y ejecución sobre el sistema de consultas populares de conformidad con lo que disponga la Ley a la que se refiere el artículo 92.3 de la Constitución y las demás leyes del Estado en los términos previstos en el artículo 149.1.32 de la Constitución (32).

En ambos casos, y a pesar del titulo competencial específico sobre consultas populares establecido por los diferentes estatutos, es necesario reconducir su regulación a la competencia estatal para fijar las bases del régimen jurídico de las Administraciones públicas, y en concreto de la Administración local, de conformidad con el artículo 149.1.18 de la Constitución. Y ello porque el legislador estatal ha incardinado el régimen jurídico de las consultas populares locales en el marco de la Ley de Bases de régimen local, de forma que las Comunidades Autónomas no pueden desconocer este título competencial ni el contenido básico de estos preceptos.

Pero además aquellos preceptos de los Estatutos de Autonomía que atribuyen competencia autonómica sobre consultas populares de conformidad con el artículo 92.3 y 149.1.32 de la Constitución (33), se están refiriendo, a pesar del término utilizado, únicamente a los supuestos en que tales consultas populares revisten la consideración de referéndum, circunstancia que como hemos visto no concurre en el caso de las consultas populares de ámbito local, que quedan fuera de este título y se inscriben en la competencia sobre las bases de régimen local.

La necesidad de autorización de las consultas populares por parte del Gobierno, se justifica en la regulación efectuada por el legislador estatal en

(31) Ver artículo 122 de la Ley Orgánica 6/2006 de 19 de julio de Reforma del Estatuto de Autonomía de Cataluña. Un comentario sobre esta cuestión puede verse en LÓPEZ DE LERMA I LÓPEZ, J., "La dudosa competencia exclusiva de la Generalitat de Cataluña para promover consultas populares», Diario La Ley N. ${ }^{\circ} 6810,1007$.

(32) Es el caso del Estatuto de Autonomía de las Islas Baleares en la redacción dada por la Ley Orgánica 3/1999 de 8 de enero de Reforma del citado estatuto. En un sentido similar puede verse la Ley Orgánica 2/1999 de 7 de enero de Reforma del Estatuto de Autonomía de la Rioja.

(33) El articulo 71 del Estatuto de Autonomía de Castilla y León se refiere a esta misma cuestión aunque remitiendo no sólo al artículo 92.3 de la Constitución sino también a las demás leyes del Estado. 
base al art. 149.1.18, una vez excluida su naturaleza jurídica de referéndum, y por tanto la imposibilidad de sustentar dicha autorización en el artículo 149.1.32 de la Constitución. Así se recoge en el Dictamen del Consejo de Estado 1070/2001 emitido en relación al Real Decreto regulador del procedimiento de autorización por el Gobierno de la Nación de las consultas populares municipales, que finalmente no ha llegado a aprobarse. Pues bien, la D.F 1. ${ }^{\text {a }}$ de dicho proyecto estableció que se dictaba al amparo de lo dispuesto en el artículo 149.1.18 de la Constitución. Y al respecto el Dictamen mencionado señaló: "De acuerdo con reiterada doctrina del Tribunal Constitucional, la regulación en una norma reglamentaria de aspectos básicos de una materia constituye una excepción que se justifica en que tales aspectos resulten complementos necesarios para garantizar el fin a que responde la competencia estatal sobre las bases" (34).

Según esta distribución de competencia, el artículo 71 de la LRBRL contiene la disciplina básica sobre la institución de las consultas populares, que deberá ser observada por las Comunidades Autónomas que la desarrollen en base a sus competencias sobre régimen local.

\section{La configuración legal de las consultas populares}

A la vista de las consideraciones anteriores, puede decirse que las consultas populares reguladas en el ámbito de la Administración local son un cauce de participación articulado por la Ley que no tiene un reconocimiento constitucional expreso, sino que deriva de los valores y principios propugnados por la Constitución. Ha sido por tanto el legislador ordinario el que ha decidido dotar al ámbito local de esta forma de participación en la adopción de decisiones administrativas.

La regulación de las consultas populares hay que buscarla en primer lugar en la Ley 7/85 de 2 de abril, que con carácter de legislación básica ha previsto su existencia, sus modalidades, y los requisitos para su ejercicio y a la que remite la Disposición Adicional Única de la Ley 2/80 de 18 de enero, que regula las distintas modalidades de referéndum. La citada norma establece que su regulación no alcanza a las consultas populares que puedan celebrarse por los Ayuntamientos, relativas a asuntos relevantes de índole municipal en sus respectivos territorios, que se regirán por la legislación de régimen local, añadiendo que queda "a salvo en todo caso, la competencia exclusiva del Estado para su autorización".

Fue la Ley 57/2003 de 16 de diciembre de Modernización del Gobierno local la que profundizó en su regulación al introducir el artículo 70 bis en

(34) Dictamen del Consejo de Estado 1070/2001. 
la Ley 7/85 de 2 de abril (35). A través de dicho artículo la Ley establece los requisitos y cauces procedimentales para hacer efectivo un derecho que ya estaba reconocido en el artículo 18 de la Ley de Bases de régimen local y que formaba parte del estatuto de los vecinos, pero respecto al cual la citada Ley no añadía mayores precisiones.

De acuerdo con la regulación actual existen dos modalidades de consultas: a petición popular y a iniciativa de la corporación. Esta última, en la cual es la propia Administración local quien asume la iniciativa de someter un determinado asunto a consulta popular ya estaba contemplada en el articulo 71 de la Ley Reguladora de Bases de régimen local en su redacción inicial.

En cambio la consulta popular a petición vecinal estaba reconocida como un derecho de los vecinos en el artículo 18 de la LRBRL, aunque la citada Ley no contenía ninguna otra precisión, de modo que su desarrollo quedaba confiado a la legislación autonómica, que en muchos casos carecía de regulación al respecto bloqueando el ejercicio de este derecho, salvo previsión expresa en los reglamentos de organización municipal.

Tras la reforma efectuada por la Ley 57/2003 de 16 de diciembre, el derecho de los vecinos a pedir la celebración de la consulta se asocia con el derecho a ejercer la iniciativa popular (36), regulada en el artículo 70 bis de la LBRL, a través de la cual es posible plantear también la propuesta de celebración de la consulta, aunque en tal caso el procedimiento a seguir será el previsto en el artículo 71 de la LBRL (37). La iniciativa popular para presentar propuestas de actuación o proyectos normativos puede llevar incorporada una propuesta de celebración de consulta popular, en cuyo caso constituye un cauce para su ejercicio.

La participación ciudadana alcanza así su máxima expresión pues supone no sólo la propuesta por parte de los vecinos de un proyecto, actuación o reglamento, sino también la apreciación de su relevancia y la petición de su sometimiento a consulta popular.

Algunas Comunidades Autónomas también han regulado sobre consultas populares. Sólo las Comunidades Autónomas de Cataluña, Navarra

(35) Ver el comentario de FERNÁNDEZ RAMOS, S., al artículo 70 bis en la obra colectiva Comentarios a la Ley reguladora de las Bases de régimen Local, tomo II, dirigido por REBOLLO PUIG, M., Valencia, 2007, Págs. 1777 y ss. Sobre este artículo puede verse igualmente la obra colectiva Modernización del Gobierno Local, Comentarios a la Ley $57 / 2003$ de 16 de diciembre, El consultor de los Ayuntamientos y Juzgados, 2004, Pág. 158 y ss.

(36) Sobre la iniciativa popular puede verse GARCíA GARCIA, M.J., "La participación ciudadana en la elaboración de disposiciones reglamentarias: participación funcional e iniciativa reglamantaria”, obra cit. N. ${ }^{\circ} 37,2008$.

(37) Téngase en cuenta que el artículo 18 reconoce dos derechos subjetivos distintos en sus apartados f) y h), aunque procedimentalmente confluyen en un único cauce con ocasión de su planteamiento, para disociarse procedimentalmente después en atención al contenido que incorpora la iniciativa popular. 
y Andalucía (38) contienen leyes específicas sobre esta materia (39). En la mayoría de los casos las referencias a las consultas populares se encuentran en el seno de la legislación autonómica de régimen local. Así ocurre en las Comunidades autónomas de Baleares (40), Aragón (41), Galicia (42), La Rioja (43), y Madrid (44).

La forma en que la legislación autonómica contempla el derecho a pedir la celebración de las consultas populares difiere en algunos aspectos de lo previsto en la legislación estatal porque las normas autonómicas no suelen vincular la petición de las consultas con el ejercicio de la iniciativa popular como hemos visto que hace la Ley de Bases de Régimen Local (45).

Téngase en cuenta que el derecho a ejercer la iniciativa popular y el derecho de petición de consultas populares constituyen dos ámbitos diferenciados que las Comunidades Autónomas pueden regular con carácter independiente, como así resulta de la mayoría de las normas autonómicas vigentes en esta materia, y que el artículo 70 bis de la Ley de Bases de Régimen Local plantea la incorporación de la petición de consulta a la iniciativa popular como una mera alternativa o posibilidad, permitiendo que ambas puedan regularse y plantearse de manera independiente.

De acuerdo con ello cabe concluir que la petición de celebración de consultas populares por parte de los vecinos admite distintas modalidades:

- A través del cauce de la iniciativa popular, y vinculada a la presentación de una propuesta de acuerdo, decisión o proyecto de reglamento, de conformidad con el artículo 70 bis de la LRBRL. La Ley

(38) Un comentario a la regulación de esta Ley puede verse en NUÑEZ LOZANO, C. «Las consultas populares locales", Revista Andaluza de Administración pública N. 42, 2001, pág. 427-439. Igualmente RODRÍGUEZ ÁLVAREZ, J.L., "Una primera aproximación a la Ley de regulación de las consultas populares locales en Andalucía 2/2001, de 3 de mayo", Revista de Estudios de la Administración local, n. ${ }^{\circ}$ 286-287, Pág. 457-493.

(39) Ley Foral 27/2002 de 28 de octubre, Ley 2/2001 de 3 de Mayo de la Comunidad Autónoma de Andalucía, ambas reguladoras de las consultas populares locales en Andalucía, y Decreto 294/1996 de 23 de julio, por el que se aprueba el Reglamento de consultas populares municipales de Cataluña.

(40) Véase artículo 123 de la Ley 20/2006 de 15 de diciembre, municipal y de régimen local de las Islas Baleares.

(41) Ver artículo 157 de la Ley aragonesa 7/1999 de 9 de abril, reguladora de la Administración local.

(42) Véase artículo 257 de la Ley 5/1997 de 22 de julio de Administración local de la Comunidad Autónoma de Galicia.

(43) Ver artículo 168 de la Ley 1/2003 de 3 de marzo, reguladora de la Administración Local de la Rioja.

(44) Ver Ley 2/2003 de 11 de marzo de Administración local de la Comunidad Autónoma de Madrid.

(45) Únicamente la Ley Foral 11/2004 de 29 de octubre de Administración local permite en su artículo 96 bis que la iniciativa popular lleve incorporada una propuesta de consulta popular local. 
Foral 11/2004 de 29 de octubre sobre Administración local establece esta misma forma de ejercicio, si bien la legislación específica sobre consultas populares prevé también que la petición de las mismas se realice de manera independiente.

- Desvinculada de la iniciativa popular, pero ejercida de manera colectiva, en aquellas Comunidades Autónomas que teniendo su propia regulación no hayan previsto la forma de ejercicio anterior. En este caso puede observarse que las normas autonómicas exigen unos porcentajes de firmas para presentar la solicitud que no suelen coincidir con los porcentajes exigido en el artículo 70 bis de la LRBRL, dado que lo que este artículo regula es el ejercicio del derecho de iniciativa popular, al que se incorpora la petición de consulta, en tanto que las normas autonómicas están regulando el ejercicio del derecho de petición de consultas de manera independiente, de modo que no se encuentran vinculadas por los porcentajes recogidos en la legislación estatal.

\section{La naturaleza jurídica de las consultas populares promovidas a iniciativa vecinal}

\section{La solicitud de consultas populares como derecho subjetivo de los vecinos}

De acuerdo con el artículo 18 de la LRBRL la petición de consulta popular constituye un auténtico derecho público subjetivo de los vecinos, que implica el ejercicio de una petición o pretensión fundada en Derecho ante la Administración y cuyo desconocimiento engendra una verdadera y autentica reclamación. La titularidad corresponde a los vecinos aunque su ejercicio requiere que la solicitud sea suscrita por el porcentaje correspondiente de firmas.

El contenido del derecho que se confiere a los vecinos en relación con la solicitud de tales consultas comporta la obtención de una respuesta motivada de la Administración sobre la petición formulada, debiendo el Pleno de la Corporación, de forma fundada, denegar la solicitud de celebración o aprobarla, en cuyo caso el Alcalde deberá solicitar autorización al Gobierno de la Nación para la celebración de la misma (46).

El derecho a solicitar la consulta no implica que efectivamente haya de celebrarse la misma, sino el derecho a poner en marcha el procedimiento adecuado para determinar su procedencia y obtener una resolución debidamente motivada y fundada en derecho, susceptible de recurso conten-

(46) Sentencia del Tribunal Superior de Justicia de la Comunidad Foral de Navarra de 11 de octubre de 2002 . 
cioso administrativo (47), a lo que se equipara a efectos de control jurisdiccional la denegación por silencio administrativo.

El procedimiento establecido a tal efecto resulta del artículo 71 de la Ley de Bases de Régimen Local, y se aplica tanto cuando la solicitud se plantea a través del cauce de la iniciativa popular previsto en el artículo 70 bis de la LRBRL, como cuando dicha solicitud se desvincula de la iniciativa popular de conformidad con lo previsto en la legislación autonómica. De acuerdo con la legislación básica de régimen local el acuerdo de celebración requerirá mayoría absoluta del pleno y para su convocatoria será necesaria autorización del Gobierno de la Nación.

Así pues, la tramitación de la petición formulada se contrae a la celebración del pleno y votación sobre la procedencia de celebrar la consulta, elevando, de estimarse pertinente al Gobierno de la Nación la solicitud de la autorización pertinente.

Pero la configuración de la consulta popular a petición de los vecinos como un derecho subjetivo no siempre ha estado tan clara a pesar del reconocimiento expreso del artículo 18 de la Ley Reguladora de Bases de Régimen local. A ello ha contribuido la falta de una regulación más detaIlada para su ejercicio por la propia legislación estatal, y la ausencia de un cauce o procedimiento para el ejercicio de este derecho tanto en la propia Ley de Bases de Régimen Local hasta su modificación por Ley 57/2003, como en la mayoría de las normas autonómicas (48), que salvo algunas excepciones (49) no han regulado esta cuestión hasta fechas relativamente recientes.

Significativa es en este sentido la Sentencia del Tribunal Superior de Justicia de Navarra de 22 de junio de 2001 que aplicando el artículo 69 de la Ley Foral 6/99 sobre Administración local estimó que la petición de consultas populares no puede considerarse integrada en el ámbito del artículo 23 de la Constitución, razón por la cual las consultas populares están previstas como una posibilidad o facultad que se otorga a los Alcaldes para realizarlas si lo estiman conveniente, pero no como un derecho que puede ser exigido por el ciudadano por no formar parte del contenido esencial del derecho fundamental a participar en los asuntos públicos (50).

(47) En este sentido, la STS de 14 de noviembre de 1989. En el mismo sentido y con cita de la sentencia anterior puede verse la Sentencia delTribunal Superior de Justicia de Navarra de 11 de octubre de 2002.

(48) Véase en este sentido la STS de 14 de noviembre de 1989.

(49) Así por ejemplo Cataluña, que reguló las consultas populares a través del Decreto 294/1996 de 23 de julio, la Comunidad Autónoma Gallega, que ya contenía una referencia a las consultas populares en la Ley de 22 de julio de 1997, o la Comunidad Autónoma de Aragón que aludía a las consultas populares en su Ley de Régimen Local de 9 de abril de 1999.

(50) Hay que tener en cuenta que en la Comunidad Foral de Navarra la regulación de las consultas populares no se realiza hasta que no se aprueba la Ley de 6 de noviembre de 2002. 
Efectivamente podemos estar de acuerdo en que la petición de las consultas por parte de los administrados no constituye un derecho fundamental derivado del artículo 23 de la Constitución. Pero al margen de ello la citada sentencia parece desconocer el derecho de configuración legal reconocido a los vecinos en el artículo 18 de la Ley de Bases de Régimen local derivado de los principios y valores constitucionales referentes a la participación de los administrados.

Se trata en todo caso de una línea jurisprudencial ya superada pues tanto la regulación efectuada por la Ley 57/2003 de 16 de diciembre como el tratamiento que en los últimos años han dispensado las normas autonómicas permiten configurar la petición de consulta como derecho subjetivo dotado de todas las garantías para su ejercicio.

\section{Distinción del derecho de petición}

La consideración de la solicitud de celebración de consultas populares como un derecho subjetivo, se aprecia con mayor claridad al contrastarlo con otras figuras como pueden ser el derecho de petición (51) o el derecho de iniciativa individual recogido en el artículo 231 del ROF regulado como una modalidad del derecho de petición (52).

En efecto, el derecho de petición presenta un contenido que lo configura como un instrumento de participación ciudadana en la medida en que puede incorporar sugerencias, iniciativas, suplicas o quejas razón por la cual presenta una cierta similitud con el derecho a proponer la celebración de consultas populares y con la iniciativa popular. Todas ellas son manifestaciones de participación directa de los ciudadanos en los asuntos públicos (53). Ahora bien, se distinguen por la delimitación negativa del derecho de petición que excluye cualquier pretensión con fundamento en la alegación de un derecho subjetivo o un interés legítimo especialmente protegido. En definitiva el derecho de petición ha de referirse en todo caso a decisiones discrecionales o graciables que no tienen un cauce procedimental específico.

La jurisprudencia ha perfilado su contenido, al indicar que en él queda comprendido el derecho a que el escrito de petición sea admitido, se le de el curso correspondiente y se tome en consideración, sin que de ello pueda derivarse perjuicio alguno para el peticionario. El derecho de peti-

(51) Ver en este sentido la Sentencia delTribunal Supremo de 14 de noviembre de 1989.

(52) Este precepto presenta la peculiaridad de que si la propuesta llegase a ser objeto de tratamiento por algún órgano colegiado municipal, su presidente «podrá requerir la presencia del autor de la propuesta en la sesión que corresponda a los efectos de explicarla y defenderla por si mismo».

(53) Sobre estas cuestiones puede verse MONTIEL MÁROUEZ, A., «EI derecho de petición: ¿instrumento de participación directa de los ciudadanos, o manifestación de la función de control?», Cuadernos constitucionales de la Cátedra Fadrique Furió Ceriol, N. ${ }^{\circ} 30-31$, pag. 137 y ss. 
ción sólo obliga a la Administración Pública destinataria a acusar recibo de la recepción y a comunicar al peticionario interesado la decisión que se adopte, que obviamente puede ser la de su archivo. No incluye el derecho a obtener respuesta favorable a lo solicitado, pero desde la perspectiva del destinatario origina dos obligaciones para la organización pública receptora: una al principio, exteriorizar el hecho de la recepción, y otra al final, consistente en comunicar al interesado la decisión que se adopte (54).

Nada tiene que ver con la solicitud de celebración de consulta popular que supone el ejercicio de una petición o pretensión fundada en derecho ante la Administración, que constituye y engendra una verdadera y auténtica reclamación (55).

Precisamente estas dos circunstancias, es decir la existencia de un procedimiento especifico para determinar la procedencia de la consulta y la posibilidad de plantear el correspondiente recurso en caso de que se entienda vulnerado el derecho a promover la consulta popular permiten distinguirlo del derecho de petición, caracterizado por su carácter genérico, residual y graciable.

Por esta razón, es decir para conferir a la petición de celebración de consultas populares el carácter de un auténtico derecho subjetivo, no basta con definirlo como tal, sino que es necesaria una regulación concreta de su contenido y del procedimiento adecuado para su ejercicio a fin de contar con parámetros expresos de legalidad que permitan resolver motivadamente la aceptación o denegación de la consulta y sometar la decisión que se adopte al control judicial.

\section{El ámbito subjetivo de las consultas populares}

\section{El ejercicio del derecho de petición de consultas populares}

La regulación de consultas populares a petición vecinal permite distinguir dos ámbitos bien diferenciados. Por una parte la legitimación para proponer la celebración de la consulta, y por otra los requisitos de participación en la misma, una vez que ésta ha sido aprobada por el Pleno y autorizada por el Gobierno.

La Ley Reguladora de Bases de Régimen Local permite vincular la petición de consulta con el ejercicio del derecho de iniciativa popular al que acompaña, en cuyo caso los requisitos formales para plantear la solicitud son lo mismos que el artículo 70 bis exige para el ejercicio de la iniciativa popular.

(54) En este sentido pueden verse las STC 161/1988 y 242/1993 de 14 de julio.

(55) En este sentido puede verse la STS de 14 de noviembre de 1989. 
Según el citado artículo no basta con ostentar la condición de vecino del municipio, sino que además es necesario gozar del derecho electoral de participación activa en las elecciones municipales. Sin embargo el porcentaje de participación exigido para plantear válidamente la iniciativa popular no se calcula tomando en consideración a los vecinos que gozan del derecho de sufragio activo, sino a todos los habitantes del municipio, es decir que sólo pueden plantearla los vecinos titulares del derecho de sufragio activo, pero el porcentaje de participación queda referido a la totalidad de los vecinos (56).

Con anterioridad a la modificación de la Ley 7/85 de 2 de abril por Ley $57 / 2003$, existía un vacío legal en relación con el ejercicio del derecho de petición de consultas populares en aquellas Comunidades Autónomas que no habían regulado esta materia, y que se solventó por la jurisprudencia reconociendo con gran amplitud la posibilidad de su ejercicio a favor de las asociaciones ciudadanas (57). Sin embargo el contenido del artículo 70 bis de la Ley Reguladora de Bases de Régimen Local articula un cauce de participación para el que ya no resultan relevantes las asociaciones vecinales (58) sino el porcentaje de firmas recabado, lo que dificulta considerablemente el ejercicio de este derecho.

Por otra parte, en aquellas Comunidades Autónomas que sí han legislado sobre consultas populares, la inclusión de estos requisitos porcentuales en la legislación básica plantea algunos problemas de adecuación con el contenido de las normas autonómicas.

La divergencia entre ambas legislaciones puede observarse contrastando el contenido del artículo 70.2 bis con dichas normas autonómicas. Así por ejemplo, la Ley del Parlamento de Andalucía, reguladora de las consultas populares locales (Ley 2/2001 de 3 de mayo), contiene en su artículo 6 niveles porcentuales menos exigentes que los previstos en la legislación estatal (59). Por su parte el Decreto 294/1996 de 23 de julio, por el que se aprueba el Reglamento de Consultas populares municipales en Ca-

(56) Así, según el apartado segundo del artículo 70 bis de la Ley Reguladora de Bases de Régimen Local, hasta 5.000 habitantes se exige el $20 \%$. De 5.000 a 20.000 habitantes, el $15 \%$. A partir de 20.0001 el $10 \%$.

(57) Así por ejemplo la STS de 14 de noviembre de 1989 reconoce esta posibilidad a la denominada Comisión Ciudadana pro metro de Sevilla.

(58) Sobre este punto puede verse MONTIEL MÁROUEZ, A. "La participación ciudadana en la vida local. La consulta popular», UNED. Boletín de la Facultad de Derecho N. ${ }^{\circ} 28,2006$, Pág. 115 y ss.

(59) En municipios de hasta 5.000 habitantes, el 10\% de los mismos.

En municipios de 5.001 a 50.000 habitantes, 500 más el 7\% de los habitantes que excedan de 5.000 . En los municipios de 50.001 a 100.000 habitantes, 3.650 más el $5 \%$ de los habitantes que excedan de 50.000 .

En los municipios de más de 100.000 habitantes, 6.150 más el tres por ciento de los habitantes que excedan de 100.000. 
taluña establece también sus propios porcentajes al respecto (60). Y en las antípodas de la legislación estatal, hay que citar la Ley de consultas populares del Parlamento de Navarra que exige como requisito para plantear la solicitud de consulta que ésta haya sido suscrita por un número de firmas que como mínimo sea igual al $10 \%$ de los censados en el correspondiente municipio, porcentaje que se aplica invariablemente con independencia de la población del mismo.

El artículo 70 bis de la Ley Reguladora de Bases de Régimen Local establece que lo dispuesto en dicho precepto se entiende sin perjuicio de la legislación autonómica en la materia. Esta afirmación legal viene a suponer que la legislación básica estatal actúa como una legislación de máximos (61), estableciendo unos umbrales porcentuales que las Comunidades autónomas no podrán en ningún caso superar, pero que en el contexto de su propia regulación si podrán ser rebajados. Y esta misma posibilidad es admisible para las ordenanzas municipales, siempre que se sitúen en el marco habilitado por la legislación autonómica.

Por otra parte, los porcentajes exigidos por la legislación estatal se refieren al ejercicio de la iniciativa popular para presentar propuestas de acuerdos, actuaciones o proyectos de reglamentos a los que la ley permite que se incorpore la solicitud de consulta popular. Pero en realidad se trata de dos derechos diferenciados cuya regulación y ejercicio puede realizarse de manera independiente. De esta manera, las Comunidades Autónomas pueden optar por desvincularlos, regulando con carácter independiente la petición de consultas populares, como así hace la legislación catalana, navarra y andaluza en sus normas específicas, así como otras normas autonómicas que sin disponer de legislación específica sobre consultas populares, contienen referencias a las mismas en las normas de régimen local (62). En tal caso entendemos que ya no son aplicables, ni siquiera con el carácter de máximos, los porcentajes del artículo 70 bis.

(60) Así, en su artículo 3 establece los siguientes porcentajes:

- El $20 \%$ de los habitantes, en poblaciones de 5.000 habitantes o menos.

- 1.000 más el $10 \%$ de los habitantes que excedan los 5.000 habitantes en las poblaciones de 100.000 habitantes o menos.

- 10.500 más el $5 \%$ de los habitantes que excedan los 100.000 habitantes, en las poblaciones de más de 100.000 habitantes.

(61) Una valoración sobre los porcentajes fijados en la ley puede verse en MONTIEL MARQUEZ, A., "La participación ciudadana en la vida local. La consulta popular», obra cit., pag. 142.

(62) La legislación sobre Administración local de Aragón, La Rioja y las Islas Baleares (ya citadas) establecen los siguientes porcentajes:

- el $20 \%$ de los habitantes en poblaciones de menos de 5.000 habitantes.

- 1.000 habitantes más el $10 \%$ de los habitantes que excedan de los 5.000 en poblaciones de 5.000 a 100.000 habitantes.

- 10.000 habitantes más el $5 \%$ de los habitantes que excedan de los 100.000 , en poblaciones de más de 100.000 habitantes. 
Estos mismos argumentos sirven para amparar una regulación autonómica en la que el derecho de petición de la consulta puede ejercerse por la totalidad de los vecinos sin la restricción impuesta por las normas básicas que exigen además la concurrencia de otro requisito cual es el derecho de sufragio activo en las elecciones municipales (artículo 70 bis de la LRBRL). En esta línea cabe citar la Ley Navarra sobre consultas populares (63), así como el artículo 168 de la Ley sobre Administración Local de la Comunidad Autónoma de la Rioja y el artículo 157 de la Ley de Administración Local de la Comunidad Autónoma de Aragón.

\section{Legitimación para participar en la consulta}

Además de los requisitos de legitimación subjetiva para plantear la iniciativa popular (con propuesta de celebración de consulta popular) ha de hacerse referencia también a la legitimación para participar en la consulta popular y expresar a través de ella la opinión respecto a un asunto de especial relevancia local. El artículo 71 de la Ley de Bases de Régimen Local únicamente contiene una alusión a los vecinos para indicar que podrán someterse a consulta popular aquellos asuntos que sean de especial relevancia para sus intereses, con lo que podría entenderse que para participar en la consulta no es necesario ostentar el derecho de sufragio activo, sino que basta con poseer la condición de vecino. Precisamente esta cuestión se plantea toda vez que la Ley 4/96 de 10 de enero desvincula la condición de vecino de la titularidad de los derechos de participación política.

La legislación autonómica ofrece regulaciones muy variadas en este sentido. Así por ejemplo la Ley andaluza que regula las consultas populares locales establece en su artículo 15 que el cuerpo electoral que podrá expresar su opinión en la consulta lo constituyen los vecinos del municipio que al tiempo de la convocatoria de la misma gocen del derecho de sufragio activo en las elecciones municipales. En un sentido similar ha previsto la participación en las consultas el Decreto 294/1996 de 23 de julio en su artículo 10. Esta cuestión es importante, puesto que supone excluir del ejercicio de este derecho a un colectivo en ocasiones muy numeroso en algunos municipios como son los extranjeros no comunitarios, que una vez inscritos en el Padrón Municipal ostentan la condición de vecinos, según el artículo 15 de la Ley Reguladora de Bases de Régimen Local.

Más permisiva resulta en cambio la Ley del Parlamento de Navarra, reguladora de las consultas populares de ámbito local, que atribuye el derecho a

(63) El artículo 6.3 de la Ley de Andaluza de consultas populares señala que sólo pueden suscribir la solicitud los vecinos del municipio que gocen del derecho de sufragio activo en las elecciones municipales. En el mismo sentido, el artículo 2.3 del Decreto catalán 294/1996 de 23 de julio. 
expresar su opinión en la consulta mediante su voto a los vecinos y vecinas del municipio que, al tiempo de la convocatoria, sean mayores de edad y estén inscritos en el padrón municipal. Coherentemente con esta amplitud en el reconocimiento del derecho, la citada Ley admite que la iniciativa de la consulta pueda suscribirse por los vecinos del municipio que siendo mayores de edad estén registrados en el Padrón municipal. En mi opinión me parece esta una opción mucho más acertada y plausible que la de supeditar la participación al derecho de sufragio activo en las elecciones municipales. Téngase en cuenta que en este caso no estamos hablando de un instrumento de la democracia directa o representativa, ni de un derecho que comporte el ejercicio de poder político, para lo cual es imprescindible ostentar el derecho de sufragio activo, sino una manifestación de la democracia participativa, a través del cual es posible expresar una opinión sobre un asunto relevante de interés local y de naturaleza administrativa. $Y$ este asunto puede ser de especial relevancia para los vecinos con independencia del reconocimiento de un derecho de participación política. Por esta vía podría incluso reconocerse a los vecinos mayores de 16 años.

Cuestión distinta es el reconocimiento de este derecho a personas que no ostenten la condición de vecino por no figurar inscritos en el correspondiente padrón de habitantes. Es decir ¿podría ampliarse el ámbito subjetivo de este derecho a todos aquellos que pudieran tener intereses en el ámbito municipal a pesar de no estar empadronados y por ende no ostentar la condición de vecinos? (64) La cuestión no es meramente hipotética, sino que llegó a plantearse con ocasión de la impugnación de parte del articulado de la Carta de Participación Ciudadana del Ayuntamiento de la Eliana, por considerar que el citado documento negaba el derecho de participación a los ciudadanos no empadronados pero que pudieran tener intereses en el municipio, contraviniendo el principio de igualdad. En este sentido es necesario señalar que los mecanismos de participación ciudadana van fundamentalmente referidos a quieres fueran vecinos de la corporación local, no a quienes no lo son, puesto que el transeúnte actualiza su derecho de participación allí donde sea vecino.

El artículo 18 de la Ley Reguladora de Bases de Régimen Local es claro en este sentido al referirse a los derechos y deberes de los vecinos (65). Un reglamento municipal no puede regular aspectos del derecho de participación al margen de lo que dispone la ley, razón por la cual ha de entenderse que la titularidad y el ejercicio de estos derechos quedan restringidos a aquellos que tengan la condición de vecinos. El ámbito de la consulta es el

(64) En este sentido puede citarse la Sentencia del Tribunal Superior de Justicia de la Comunidad Valenciana de 15 de febrero de 2002.

(65) Con excepción quizá del artículo 18.1 e) que puede predicarse de todos los ciudadanos de conformidad con el artículo 70 de la LRBRL y 35 de la Ley 30/92 de procedimiento administrativo. 
municipio. La Ley habla de asuntos que sean de especial relevancia para los vecinos y estos adquieren esta condición por su residencia en el municipio y por estar inscritos en el Padrón municipal de habitantes.

\section{El objeto de las consultas populares y sus requisitos}

\section{El objeto de las consultas populares: requisitos materiales y competenciales}

El artículo 71 de la LRBRL alude al ámbito objetivo de las consultas populares indicando que ha de tratarse de asuntos de la competencia propia municipal, y de carácter local, que sean de especial relevancia para los intereses de los vecinos, con excepción de los relativos a la Hacienda Local. El ámbito objetivo de las consultas populares es necesariamente más reducido que el de la iniciativa popular pues para que prospere la iniciativa popular y sea debatida por el pleno, el artículo 70 bis de la LRBRL tan sólo exige que se trate de materias de la competencia municipal.

La jurisprudencia ha destacado que los requisitos objetivos previstos en el artículo 71 de la Ley 7/85 de 2 de abril son concurrentes, "y dados los términos en que se formulan, revelan un designio del legislador ciertamente restrictivo respecto de esta fórmula de participación popular en el procedimiento de adopción de decisiones municipales, inspirado en el sistema de representatividad electiva" (66).

Varias precisiones pueden hacerse en relación con este precepto. En primer lugar implica que los asuntos han de ser de la competencia propia municipal. Este requisito contrasta con el contenido en el artículo 70 bis, que habla únicamente de asuntos de competencia municipal. Con esta expresión, el precepto declara expresamente que no cabe proyectar el ejercicio de consultas populares sobre competencias delegadas, y que el ámbito de aplicación de este derecho es el de las competencias propias, es decir de aquellas que el municipio ejerce en régimen de autonomía y bajo su propia responsabilidad.

En este sentido hay que tener en cuenta la forma de delimitación del ámbito competencial de las entidades locales. La autonomía local se constituye al amparo de la garantía institucional que establece la Constitución, lo que significa que no existe un ámbito competencial previamente diseñado por el constituyente, sino que éste se configura por el legislador básico primero y sectorial después Esto implica que no existen competencias exclusivamente de carácter local, pues no hay ámbitos competenciales exentos cuyo interés corresponda única y ex-

(66) En este sentido puede verse la STS de 17 de febrero de 2000. 
clusivamente a la Administración local. Por tanto, no cabe identificar las competencias propias a que se refiere el artículo 71 de la Ley de Bases de Régimen local con competencias municipales exclusivas, ni plantear como conceptos antagónicos el ámbito de las competencias propias de carácter local con ámbitos competenciales concurrentes con otras Administraciones públicas en relación con una misma materia y ámbito territorial. Precisamente uno de los ámbitos en que se manifiesta de forma evidente esta concurrencia competencial es el urbanismo, materia que forma parte de las competencias propias del municipio según el artículo 25 de la $L R B R L$, pero donde la diversidad de intereses presentes hacen de la misma una materia de titularidad compartida por los municipios y las Comunidades Autónomas. En este sentido es imprescindible citar la STS de 23 de septiembre de 2008 que resuelve el recurso contencioso-administrativo interpuesto contra el acuerdo del Consejo de Ministros de 1 de septiembre de 2006, por el que se deniega al Ayuntamiento de Almuñecar (Granada) la preceptiva autorización para la celebración de una consulta popular relativa a la aprobación inicial del Plan General de Ordenación Urbana del Municipio. El Consejo de Ministros justifica la denegación de la autorización al entender que el asunto que el Ayuntamiento de Almuñecar pretendía someter a consulta popular, en concreto la aprobación inicial de un plan municipal de urbanismo, no entraba dentro del ámbito de las competencias propias municipales, al estar asignada la aprobación definitiva de los referidos planes a la Administración autonómica. ElTribunal Supremo, partiendo del presupuesto de que los asuntos de la competencia propia municipal no equivalen a asuntos de la competencia exclusiva del municipio, anula el mencionado acuerdo, señalando que la concurrencia competencial que se plantea en la aprobación del planeamiento general, no debe oscurecer el principio de que la ordenación urbanística del territorio municipal es tarea que corresponde fundamentalmente al municipio, y que la intervención de otras Administraciones se justifica sólo en la medida en que concurren intereses de carácter supramunicipal o controles de legalidad que se atribuyen a las Administraciones supraordenadas sobre las inferiores. Desde estos argumentos, la sentencia analizada afirma que la aprobación inicial del Plan General de Ordenación Urbana es una competencia propia municipal que habilita el planteamiento de una consulta popular (67).

Pero de la misma forma que no hay competencias exclusivamente propias de las entidades locales, tampoco la exclusividad de la competen-

(67) Véase sobre esta cuestión GARCIA GARCIA, M.J., "La celebración de consultas populares con motivo de la aprobación inicial de un plan general de ordenación urbana», que se publicará próximamente en la $R D U$ (número pendiente de determinar). 
cias por parte de otras instancias territoriales priva a las entidades locales de competencias sobre esa materia, bien sobre la base del mismo título competencial, bien sobre la base de títulos competenciales diferentes. Un buen ejemplo de estas afirmaciones lo constituye la STS de 18 de junio de 2001 en la que se cuestionaba la competencia del municipio para decidir la instalación de antenas de telefonía. La citada sentencia señala que " $L a$ existencia de un reconocimiento de la competencia en una materia como exclusiva de la Administración del Estado no comporta, por si misma, la imposibilidad de que en la materia puedan existir competencias cuya titularidad corresponda a los entes locales.

El sistema de determinación de competencias del Estado y de las Comunidades Autónomas que se verifica en el Título VIII de la Constitución tiene como finalidad el establecer los principios con arreglo a los cuales deben distribuirse las competencias básicas, normativas y de ejecución entre el Estado y las Comunidades Autónomas, como entes territoriales investidos de autonomía legislativa. Sin embargo, no impide que la Ley, dictada con arreglo al esquema competencial citado, reconozca competencias a los entes locales ni anule la exigencia constitucional de reconocer a cada ente local aquellas competencias que deban considerarse necesarias para la protección de sus intereses en forma tal que permita el carácter reconocible de la institución».

La sentencia llega a una doble conclusión. Primero, la competencia estatal en relación con las telecomunicaciones no excluye la del correspondiente municipio para atender a los intereses derivados de su competencia en materia urbanística, con arreglo a la legislación aplicable. Y segundo, el ejercicio de dichas competencias exige la aplicación del principio de proporcionalidad, sin que su ejercicio por parte de los ayuntamientos pueda entrar en contradicción con el ordenamiento, ni traducirse en restricciones absolutas al derecho de los operadores a establecer sus instalaciones, ni en limitaciones que resulten manifiestamente desproporcionadas.

En otras ocasiones en cambio este argumento no puede aplicarse, de modo que las competencias exclusivas del Estado sobre una materia privan a la Administración local de intervención en la misma. En este sentido puede citarse la ST Superior de Justicia de Navarra, de 10 de enero de 2003 donde la consulta popular se planteó respecto a la conveniencia de retirar las fuerzas y cuerpos de Seguridad del Estado de la población de Sakana (68). La citada sentencia estimó que el acuerdo impugnado infringía el artículo 149.1.29 de la Constitución, que atribuye al Estado competencia exclusiva en materia de seguridad pública, sin que los entes locales

(68) La consulta popular se planteó en estos términos: "Ante la constante vulneración de los derechos civiles y políticos de la población de Sakana, ejercida por las Fuerzas y Cuerpos de Seguridad del Estado, ¿considera usted oportuna su inmediata retirada?». 
tengan competencia ejecutiva alguna al respecto, ni puedan con sus actos vulnerar o socavar el marco de distribución de competencias constitucionalmente establecido.

Por otra parte el precepto alude a que han de ser asuntos de carácter local, lo que a primera vista parece una redundancia, puesto que las competencias propias de la entidad local presuponen el carácter local de los asuntos. La autonomía local es el derecho a participar a través de órganos propios en el gobierno y administración de los asuntos que le atañen, pero la intensidad de esta participación habrá de graduarse en función de la relación entre los intereses locales y supralocales dentro de tales asuntos o materias. De forma que las manifestaciones de esta participación no revestirán ni la misma intensidad ni la misma formalidad dependiendo del asunto al que afecten.

Con este requisito referente al carácter local de los asuntos quizá se esté haciendo referencia a la ponderación de los intereses locales y supralocales y a la graduación de la intensidad de la participación, de forma que el "carácter local» designa aquellas materias más próximas a los intereses locales, donde la intervención y competencia de los municipios es más intensa y se manifiesta en la adopción de decisiones administrativas, por contraposición a aquellas materias en donde la competencia municipal se manifiesta no en una resolución administrativa que decide y pone fin al procedimiento, sino en la intervención en un procedimiento a través de la emisión de informes (69), o incluso asuntos en donde el municipio tiene capacidad para intervenir en un procedimiento, si bien la decisión final corresponde a otra Administración.

Ello implica valorar y poner en relación los intereses locales y supralocales presentes en una materia a efectos de determinar el grado de intervención en la misma, de forma que estarían excluidos de la consulta popular aquellos asuntos en que, en atención a estas circunstancias o al criterio del interés prevalente (70), la intervención de la entidad local reviste manifestaciones menos intensas tales como la emisión de informes, o la adopción de la iniciativa. Y si esto es así, ¿qué pasa cuando la decisión es municipal pero se requiere el informe de la Comunidad Autónoma?

(69) Así por ejemplo, el artículo 19 de la Ley de Puertos establece que las obras que realicen las Autoridades Portuarias en el dominio público portuario deberán someterse a informe de la administración urbanística competente, sin que estén sujetas a los actos de control preventivo, es decir a la obtención de licencia por parte del municipio. Estamos aquí ante un supuesto en el que la intervención del municipio en materia urbanística se articula a través de la emisión de informes que sustituyen la obtención de la previa licencia. La STC 40/1998 declaró la constitucionalidad de este precepto en atención al interés prevalente.

(70) Así por ejemplo cabe señalar la denegación de autorización para celebrar una consulta popular sobre la instalación de parques eólicos en La Jonquera, por entender el ejecutivo que la implantación de centros de producción eléctrica implica la existencia de un interés supramunicipal prevalente, lo que desvirtúa el carácter local de la consulta popular proyectada por esta localidad del Alto Empordá. 
Desde otro punto de vista, algunas sentencias han identificado los asuntos de carácter local con la extensión de los intereses afectados, delimitados por el ámbito geográfico del municipio, o lo que es lo mismo circunscritos al término municipal en que la entidad ejerce sus competencias con exclusión de asuntos de carácter supramunicipal (71). En realidad es un criterio de interpretación coincidente en gran medida con el anterior, pues la capacidad decisoria de un municipio ha de quedar restringida a aquellos asuntos que afecten exclusivamente al círculo de interés local, nunca a asuntos que superen este ámbito por tener carácter supramunicipal. Sin embargo, en materia urbanística es perfectamente posible que en el ámbito territorial afectado por el planeamiento general concurran también intereses supralocales, de forma que aunque la proyección territorial del plan quede limitada a un término municipal, resulten implicados también intereses superiores. Ello no obsta según la STS de 23 de septiembre de 2008 a considerar la ordenación urbanística municipal como un asunto de carácter local al pretender establecer el marco regulador del espacio físico de la convivencia de los vecinos, dada la presencia de intereses concurrentes en un mismo ámbito espacial. Desde este punto de vista cabe hablar de la intervención de la Comunidad Autónoma en la aprobación definitiva, ya sea para apreciar la concurrencia de intereses supramunicipales, ya para verificar un control de legalidad sobre los intereses estrictamente locales. Por esta razón, la relevancia local de los intereses afectados por el plan general de ordenación urbana no se corresponde con su aprobación definitiva por parte del municipio, pero ello no supone que la aprobación inicial no implique el ejercicio de una competencia propia municipal, ni tampoco que la decisión afectada quede fuera del marco de los asuntos de interés local, sino el ejercicio de una competencia compartida en atención a la posible concurrencia de intereses sobre un mismo territorio, y que se sustancia en el establecimiento de un procedimiento bifásico en el que a la aprobación inicial del municipio sigue en un orden temporal lógico la aprobación definitiva de la Comunidad Autónoma, limitada en su intervención al control de legalidad, y de oportunidad únicamente en aquello que se revele como de incidencia supralocal, pero sin que ello obste el principio de que la ordenación urbanística del territorio municipal es una competencia fundamentalmente municipal que afecta de manera muy estrecha a los intereses locales.

Así pues, el carácter local puede hacer referencia al hecho de que el asunto no supere los límites geográficos del municipio, o en el sentido an-

(71) Puede citarse al respecto la STS de 14 de noviembre de 1989 que transcribe literalmente la sentencia apelada, y en la que se entiende que un asunto posee carácter local cuando no supera los límites geográficos del término municipal. 
tes visto que si no es de exclusivo interés local, si al menos que no concurra un interés supramunicipal prevalente, sino en todo caso concurrente.

La jurisprudencia ofrece algunos ejemplos. Así por ejemplo el deslinde de términos municipales previsto en el artículo 18 y siguientes del Reglamento de Población y Demarcación Territorial de las Entidades Locales. La STS de Justicia de la Comunidad Valenciana de 31 de julio de 1996 resolvió que este supuesto no entraba dentro del ámbito de aplicación del artículo 71 de la Ley 7/85 de 2 de abril por entender que "no se trata de un asunto de competencia municipal sino intermunicipal».

En mi opinión, más que de un asunto de competencia intermunicipal se trata de una materia de interés supralocal, que afecta a más de un municipio, razón por la cual no puede entenderse comprendido dentro del ámbito de aplicación de las consultas populares. Es evidente que se trata de un asunto de interés local, pero el ámbito afectado supera dicho interés y por tanto las competencias de decisión corresponden a la Comunidad Autónoma aunque la intervención de la Administración local en el procedimiento de deslinde es innegable de acuerdo con los artículos 17 y siguientes del Reglamento de Población y Demarcación. De hecho cuando el interés es supralocal las competencias decisorias no corresponden al propio municipio sino que se elevan al ámbito autonómico o estatal.

Así resulta también en el supuesto que resuelve la STS de 17 de febrero de 2000 respecto a la celebración de referéndum municipal para tratar la inclusión del municipio de Algeciras y de su entorno comarcal en una nueva provincia andaluza. La citada sentencia entendió que se trataba de un asunto de carácter supralocal, puesto que la segregación de una parte de la provincia de Cádiz para la creación de una nueva provincia afectaba a otras instancias territoriales, al constituir una nueva organización provincial. El órgano jurisdiccional desestima la procedencia de la consulta popular por no darse la concurrencia de este requisito, sin entrar a determinar si «...de haber tenido carácter local, podía además, haberse considerado incluido entre los que vienen atribuidos a la competencia propia de la entidad».

Más clarificadoras resultan las sentencias del Tribunal Supremo de 24 de febrero de 1997 y 22 de enero de 1993 en donde el Tribunal Supremo se pronuncia sobre la ausencia de competencias municipales con ocasión de un recurso en el que se planteaba la posibilidad de celebrar una consulta popular sobre la incorporación de municipios pertenecientes a una Comunidad Autónoma en otra distinta, y a la posibilidad prevista en los Estatutos de Autonomía correspondientes de la celebración de una consulta en este sentido. Señala el Tribunal Supremo que es necesario diferenciar las consultas populares locales de otro tipo de consultas previstas en algunas normas autonómicas, como el Estatuto de Autonomía del País Vasco y de Castilla León, y que se incardinan en el marco de un procedimiento en virtud del cual puede producirse la segregación de un territorio o municipio perteneciente 
a una Comunidad Autónoma para pasar a formar parte de otra diferente. Estas consultas pueden celebrarse en un único municipio o en más de uno, del mismo modo que uno o más pueden ser los municipios a segregar. Por esta razón puede considerarse como municipal, atendiendo al lugar en que residen las personas que van a ser consultadas, pero sólo en este aspecto y nunca por el contenido material sobre el que recae la consulta, cuyo interés es, no ya de carácter supramunicipal sino claramente suprarregional. La consulta de segregación contemplada en el Estatuto de Autonomía de Castilla y León (72) o el País Vasco (73), sin dejar de reconocer que puede incidir de modo especial en los intereses vecinales, está fuera de la previsión del artículo 71 de la LRBRL, pues su objeto trasciende de las competencias propias municipales, y se proyecta sobre aspectos como el territorio de la Comunidad Autónoma y la condición política de sus habitantes.

Por último, ha de tratarse de asuntos de especial relevancia para los intereses de los vecinos, quedando excluidos los relativos a la Hacienda local. La especial trascendencia del asunto para los intereses de la comunidad es un concepto indeterminado cuya concurrencia parece quedar reservada al propio Ayuntamiento interpelado. Entiendo que la relevancia del asunto queda evidenciada por la propia iniciativa vecinal y el impulso dado a la misma, por lo que el margen de apreciación de la Administración debería quedar ciertamente condicionado por la iniciativa popular. En todo caso, no basta con la existencia de un interés relevante para los vecinos, sino que éste es un requisito que debe apreciarse en concurrencia con el resto las exigencias establecidas anteriormente.

\section{El objeto de las consultas populares desde un punto de vista formal}

Al margen del criterio competencial o sustantivo que ha quedado expuesto en los términos anteriores cabe también referirse al objeto de las iniciativas populares desde un punto de vista formal.

La modificación de la Ley de Bases de Régimen Local por la Ley de Modernización del Gobierno local ha establecido un ámbito considerablemente amplio sobre el que ejercer la petición de consultas populares a instancia de los vecinos al asociarlas con la iniciativa popular. En este sentido el artículo 70 bis de la Ley 7/1985 señala que la iniciativa popular podrá plantearse respecto de propuestas de acuerdos, actuaciones o proyectos de reglamentos (siempre referidos a asuntos de la competencia propia municipal, de carácter local y de especial relevancia para los intereses de los vecinos, puesto que el artículo 71 de la misma Ley endurece

(72) Disposición transitoria tercera del Estatuto de Autonomía de Castilla y León.

(73) Artículo 8 del Estatuto de Autonomía del País Vasco. 
los requisitos competenciales en el sentido ya visto anteriormente). Así pues el ámbito de las consultas populares a iniciativa vecinal es muy amplio desde un punto de vista formal y parece abarcar tanto actuaciones de carácter jurídico, como actuaciones materiales e incluso iniciativas de carácter normativo como la aprobación de reglamentos.

En todo caso, es requisito indispensable que la consulta popular se plantee respecto de proyectos de decisiones, en ningún caso sobre decisiones ya adoptadas, puesto que la consulta tal y como hemos indicado no tiene carácter de ratificación de acuerdos.

Por eso casa bien con el objeto de la iniciativa popular donde se presentan proyectos y propuestas de actuaciones o acuerdos que corresponde adoptar a la Administración local. Y confirma la opinión que hemos mantenido anteriormente en el sentido de que los asuntos a los que se refiere el artículo 71 de la LRBRL son aquellos en la Administración local tiene competencia para resolver.

\section{El procedimiento de las consultas populares}

El procedimiento para la celebración de las consultas populares pasa por varias fases hasta la celebración de las mismas. Así es necesario distinguir entre aquellas actuaciones que son previas a la convocatoria de la consulta, de los trámites posteriores a la misma.

La Ley de Bases de Régimen Local en su condición de legislación básica establece una serie de trámites que deberán ser observados por la legislación desarrollo, entre los que se encuentra la necesidad de que la celebración de la consulta popular sea acordada por mayoría absoluta del Pleno y la necesidad de autorización del Gobierno de la Nación, aspectos que serán analizados a continuación.

\section{Los acuerdos de la Administración local sobre iniciación y celebración de la consulta popular}

La iniciativa de la celebración de una consulta popular puede partir de la propia corporación, o bien de los vecinos en ejercicio de su derecho a solicitar la celebración de la misma. La Ley de Bases de Régimen Local permite en este último caso que el ejercicio del derecho de petición de las consultas populares se ejerza a través del cauce de la iniciativa popular, si bien el procedimiento a seguir no será el marcado en el artículo 70 de la LBRL, sino el previsto en el artículo 71, de forma que lo procedente será someter la iniciativa al pleno del Ayuntamiento que podrá acordar su celebración por mayoría absoluta a lo que deberá seguir la autorización del Gobierno. 
En todo caso, tanto si la iniciativa de la consulta ha sido adoptada por la corporación, como si se debe a la petición de los vecinos, es ineludible que el acuerdo de celebración se adopte por mayoría absoluta del Pleno, y que con anterioridad a la convocatoria del Alcalde exista autorización del Gobierno de la Nación.

Cuando la iniciativa de las consultas populares parte de la Administración, la decisión sobre la conveniencia de su celebración tiene carácter discrecional, ya que podrá o no adoptarse en atención a la apreciación de la relevancia de los asuntos y la conveniencia y oportunidad de someterlos a la opinión popular (74).

En cambio, cuando la petición de consulta proviene de los vecinos, nos encontramos ante el ejercicio de un derecho subjetivo de forma que la decisión de la Administración está muy condicionada por la petición popular y el cumplimiento de los requisitos formales para su ejercicio.

La decisión de someter al pleno la solicitud de consulta está supeditada al cumplimiento de una serie de requisitos sobre cuya concurrencia cabe un auténtico control jurisdiccional. En este supuesto, la Administración local a través de su Alcalde realiza un control de admisibilidad basado en criterios legales y no de carácter político de oportunidad. El sometimiento de la solicitud de consulta popular al Pleno no es una facultad discrecional del Alcalde, sino que está condicionada por el cumplimiento de los requisitos formales establecidos, de forma que si éstos concurren deberá someter la petición a la consideración de este órgano, requiriendo en caso contrario a los promotores para la subsanación de los defectos formales.

Otra cosa es el acuerdo de celebración de la consulta, que debe adoptarse por mayoría absoluta. Entiendo que la decisión de la corporación queda también muy condicionada por el porcentaje de firmas que acompañan la solicitud de consulta popular, en el sentido de que las mismas evidencian y ponen de manifiesto la importancia del asunto para los intereses vecinales, lo que facilita considerablemente la interpretación del concepto jurídico indeterminado que utiliza el artículo 71 de la Ley de Bases de Régimen Local cuando hace referencia a los «asuntos de especial relevancia para los vecinos". Hay que tener en cuenta además que el derecho a pedir la consulta popular se configura por la Ley como un derecho subjetivo, lo que implica el ejercicio de una petición o pretensión fundada en derecho ante la Administración, razón por la cual su decisión debe basarse en parámetros legales y no de oportunidad. Por tanto, la decisión del pleno sobre la celebración de la consulta no es discrecional, sino que la

(74) Precisamente algunos autores como BARATA I MIR han visto en estas decisiones un acto de naturaleza política en el ámbito de la Administración local. Los actos de gobierno en el ámbito municipal, obra cit. 
petición únicamente puede denegarse si adolece de los requisitos legales establecidos para ello.

Algunas normas autonómicas han configurado expresamente el acuerdo de celebración de la consulta popular como un acto reglado. Es el caso de la Ley del Parlamento de Navarra reguladora de las Consultas Populares, Ley Foral 27/2002, de 28 de octubre, que señala que el pleno del ayuntamiento sólo podrá denegar la convocatoria popular por falta de los requisitos exigidos para su planteamiento. En concreto podrá desestimarse en los siguientes casos, y cita: a) Cuando el asunto objeto de la iniciativa esté excluido de la consulta popular o no corresponda a la competencia municipal b) Cuando no se acompañe del número de firmas exigido, c) Cuando la propuesta se haya solicitado en un periodo de los mencionados como excluidos d) cuando la propuesta incurra en infracción del ordenamiento jurídico.

En cambio, el artículo 8 de la Ley de 3 de mayo de 2001 del Parlamento de Andalucía sobre regulación de las consultas populares introduce más elementos de juicio para apreciar la procedencia de la celebración de la consulta popular. Dicha legislación viene distinguiendo entre el acuerdo por el que se decide sobre la aprobación de la iniciación del procedimiento, es decir aceptación de la solicitud de consulta, y el acuerdo propiamente dicho de celebración, sometido al artículo 71 de la Ley de Bases de Régimen Local y para el que se exige mayoría absoluta.

El acuerdo de iniciación viene a decidir sobre la admisibilidad de la iniciativa y en realidad viene a ser un control de legalidad, de forma que cumpliéndose los requisitos formales exigidos por la Ley para plantear la petición, la Administración local no puede sino acordar la iniciación del procedimiento. La norma prevé la apertura de un trámite de información pública tras el acuerdo de iniciación, lo que no deja de resultar Ilamativo si se tiene en cuenta que el procedimiento se ha iniciado a petición de los vecinos (75). Por otro lado, si la LEY restringe el ejercicio de este derecho a los vecinos que gocen del derecho de sufragio activo, no tiene sentido la apertura de la información pública, que amplía considerablemente el ámbito subjetivo de la iniciativa de consulta permitiendo que cualquier persona física o jurídica pueda efectuar las alegaciones que considere adecuados sobre la procedencia de la misma.

En todo caso el acuerdo de celebración ha de adoptarse por mayoría absoluta del número legal de miembros de la corporación, y en el caso de que haya existido previamente un trámite de información pública, como es el caso, esta decisión se adoptará previa ponderación de las alegaciones

(75) Así por ejemplo el artículo 4 del Decreto 294/1996 de 23 de julio de la Generalitat de Cataluña, por el que se aprueba el Reglamento de consultas populares municipales. Igualmente la Ley 2/2001 de 3 de mayo, de regulación de las consultas populares locales en Andalucía, que en su artículo 8 prevé igualmente este trámite. 
presentadas, lo parece dar entrada a criterios basados en la oportunidad de la consulta. Esta regulación encaja mal con la configuración legislativa de derecho subjetivo, sometida a determinados requisitos legales, y contrasta con las normas autonómicas que han establecido los parámetros legales para la denegación la convocatoria de la consulta popular (76).

\section{La autorización del Gobierno como requisito de validez de la consulta}

Adoptado el acuerdo de celebración, la consulta popular precisa como requisito de validez la autorización del Gobierno. En el marco del complejo procedimiento de celebración de consultas populares la autorización es una de las cuestiones que ha planteado mayores problemas referentes a la naturaleza jurídica que reviste dicho acto.

Esta materia fue objeto de un proyecto de Real Decreto regulador del procedimiento de autorización por el Gobierno de la Nación de las consultas populares municipales, que finalmente no llegó a ser aprobado y que pretendió dotar a esta materia de un marco regulador en base a los principios de seguridad jurídica, cooperación y confianza legítima entre las Administraciones públicas.

En todo caso, la necesidad de autorización previa del Gobierno ha sido objeto de críticas por parte de la doctrina, que ha puesto de manifiesto el excesivo centralismo en esta materia (77) y denota la imposición de límites y restricciones que por esta vía se impone a la celebración de las consultas (78) y por ende al principio de autonomía local. Máxime teniendo en cuenta que la necesidad de autorización de las consultas populares por parte del Gobierno central no es una exigencia que derive directamente de la Constitución, que ni siquiera hace referencia al referéndum local, sino que es una exigencia recogida por la Ley de Bases de Régimen local con fundamento en el artículo 149.1.18 de la Constitución que atribuye al Estado competencia para establecer las bases de régimen jurídico de las Administraciones públicas.

En todo caso, y con mayor o menor acierto por parte del legislador, lo cierto es que la autorización del Gobierno central es un requisito de validez necesario para la celebración de la consulta, razón por la cual es necesario analizar su naturaleza jurídica, y con ello los criterios en base a los cuales

(76) Así el artículo 7.6 de la Ley Foral 27/2002 de 28 de octubre reguladora de las consultas populares de ámbito local.

(77) En este sentido IBÁÑEZ MACÍAS, A., El referéndum local en España: régimen jurídico, Universidad de Cádiz, 2005, Pág. 182 y ss.

(78) Ver MONTIEL MÁRQUEZ, A., "La participación ciudadana en la vida local. La consulta popular», obra cit., Pág. 132. 
el Gobierno ha de decidir sobre la autorización o denegación de la misma. La cuestión se centra sobre todo en determinar si el control que corresponde al Consejo de Ministros es de mera legalidad, o si cabe un control de oportunidad, de forma que la autorización o denegación de la consulta popular se traduce una decisión de carácter político.

En este sentido puede ser relevante la STC 4/1981 que vino a aclarar la procedencia de los controles de legalidad y oportunidad de las Administraciones central y autonómica sobre la Administración local.

"... que el principio de autonomía es compatible con la existencia de un control de legalidad sobre el ejercicio de las competencias, si bien entendemos que no se ajusta a tal principio la previsión de controles genéricos e indeterminados que sitúen a las Entidades locales en una posición de subordinación o dependencia cuasi jerárquica de la Administración del Estado u otras Entidades territoriales. En todo caso, los controles de carácter puntual habrán de referirse normalmente a supuestos en que el ejercicio de las competencias de la Entidad local incidan en intereses generales concurrentes con los propios de la Entidad, sean del municipio, la provincia, la Comunidad Autónoma o el Estado.

El control de legalidad, con la precisión anterior, puede ejercerse en el caso de los municipios y provincias -dado su carácter de Administraciones Públicas - por la Administración del Estado, aun cuando es posible también su transferencia a las Comunidades Autónomas en los términos que expresa el artículo 148.1, 2. ${ }^{\circ}$, de la Constitución, y, naturalmente, en uno y otro caso, siempre con la posibilidad de control jurisdiccional posterior. Ello, sin perjuicio de que el ajuste a la Constitución de la legislación de régimen local -en términos positivos, y no de evitar incompatibilidades- se producirá cuando se promulgue una nueva Ley en cumplimiento del mandato implícito contenido en la Constitución, según se indica en el epígrafe 1, $B$ «in fine», de esta sentencia.

En cambio la autonomía garantizada por la Constitución quedaría afectada en los supuestos en que la decisión correspondiente a "la gestión de los intereses respectivos" fuera objeto de un control de oportunidad de forma tal que la toma de la decisión viniera a compartirse por otra Administración. Ello, naturalmente, salvo excepción que pueda fundamentarse en la propia Constitución, como se comprobará más adelante».

Así pues, el control de oportunidad de los actos locales debe ser excepcional, pero elTribunal Constitucional no lo excluye absolutamente «siem- 
pre que su existencia pueda fundamentarse en la propia Constitución por afectar a intereses generales».

Admitida por el Tribunal Constitucional la posibilidad de controles de oportunidad sobre las decisiones de la Administración local, la cuestión a despejar es la de la naturaleza jurídica del acto del Gobierno por el que se autoriza o deniega la consulta. En este sentido cabe hacer referencia a algunas sentencias que se pronunciaron sobre esta cuestión, y en las que el Tribunal Supremo atribuyó carácter hibrido al acto del Gobierno. Hay que señalar que en estos supuestos la autorización concedida no se refería a una consulta popular de carácter local, sino al referéndum previsto en algunos estatutos de autonomía referente a la segregación de municipios pertenecientes a una Comunidad Autónoma para pasar a formar parte de otra diferente, si bien los argumentos utilizados sirven también para el supuesto que analizamos. En este sentido puede citarse la STS de 22 de enero de 1993, relativa a la celebración de un referéndum municipal en Villaverde de Trucios (79) (Cantabria) sobre su incorporación a la Comunidad Autónoma del País Vasco (80). En la citada sentencia elTribunal en su fundamento jurídico cuarto señala: "...ha de tomarse conciencia de que el acuerdo del Consejo de Ministros denegatorio del referéndum es un acto de carácter híbrido, pues si bien se trata de un alto órgano constitucional que actúa en uso de su voluntad política al autorizar o denegar el referéndum municipal, no es menos cierto que el acto ha dado lugar a un procedimiento administrativo y que para fundamentar su decisión el Gobierno ha utilizado una argumentación en Derecho, motivación del acto que es ahora combatida por la parte actora».

El Consejo de Estado ha tenido ocasión de pronunciarse sobre esta misma cuestión en algunos de sus dictámenes, otorgando al acto de autorización del Gobierno carácter administrativo, y ello en base a dos razones. En primer lugar porque a través de la autorización el Gobierno controla que la solicitud de someter la cuestión a una consulta popular municipal se ajusta a los requisitos legalmente previstos al efecto, y en segundo lugar porque la petición de autorización que formula el Alcalde es susceptible de identificarse con una solicitud formulada a instancia de parte en los términos del artículo 43.2 de la Ley $30 / 92$, lo que origina la tramitación del correspondiente procedimiento administrativo, dirigido a obtener una re-

(79) La STS de 24 de febrero de 1997 referente también a la solicitud del Ayuntamiento de Villaverde de Trucios de autorización para someter a referéndum la incorporación del municipio a la Comunidad Autónoma del País Vasco no entró a valorar la naturaleza jurídica de la autorización estatal.

(80) Con todo, hay que hacer notar que el supuesto planteado en esta sentencia no se refería a las consultas populares previstas en el artículo 71 de la Ley de Bases de Régimen local, sino que se refería al referéndum que forma parte del procedimiento previsto en el artículo 8 del Estatuto de Autonomía del País Vasco relativo a la agregación a la Comunidad Autónoma de municipios pertenecientes a otras Comunidades. 
solución administrativa que pone fin al procedimiento, lo que confirma el carácter de acto administrativo de la decisión del Gobierno.

En este sentido, el Dictamen del Consejo de Estado 1070/2001 de 21 de junio, emitido en relación con el Proyecto de Real Decreto antes citado, regulador del procedimiento de autorización de las consultas populares municipales, considera la autorización estatal de las consultas como un acto administrativo (y no político), que constituye una técnica de control externo de legalidad en materia de Régimen Local. La autorización del Gobierno se configura como un acto administrativo de control de que la solicitud de consulta popular se ajusta a los requisitos legalmente previstos al efectos, siendo estos requisitos de conformidad con el Dictamen del Consejo de Estado 943/94 de carácter material (los referentes a verificar que las consultas planteadas se refieran a asuntos de la competencia propia municipal, de carácter local y de especial relevancia para los intereses de los vecinos), y de carácter procedimental consistentes en que la petición sea solicitada por los respectivos alcaldes previo acuerdo por mayoría absoluta del pleno de la corporación. Se trata por tanto de un típico acto administrativo en donde el objeto de dicha autorización sería un control de legalidad (81).

El Dictamen 1070/2001 se reafirma en este argumento teniendo en cuenta la Sentencia delTribunal Constitucional 45/1990, según la cual una de las notas que caracteriza a las actuaciones del Gobierno no sujetas al Derecho Administrativo es que no van precedidas de una solicitud formulada por los interesados al amparo de concretas previsiones de nuestro ordenamiento jurídico y buscando una expresa resolución de ese mismo alcance. $Y$ en el caso de la petición de autorización para la celebración de consultas populares, dada la posición que ocupan, de un lado el Alcalde y el Pleno de la Corporación Municipal, que se pronuncian respecto de la solicitud de formular una consulta popular municipal, y de otro el Gobierno que debe autorizarla, parece claro que los primeros ostentan la condición de interesados definida en el artículo 31 de la Ley 30/92. Ya con anterioridad, el Dictamen del Consejo de Estado 943/94 había puesto de manifiesto que la solicitud que precede a

(81) El Dictamen del Consejo de Estado 1070/2001 señala que «...la configuración de la autorización como un acto administrativo de control de la solicitud de someter la cuestión una consulta popular municipal se ajusta a los requisitos legalmente previstos al efecto, tal y como había señalado también el Consejo de Estado en el citado dictamen 943/94, en el que se recordaba que tales requisitos eran de una doble índole: de naturaleza procedimental y expresión del adecuado equilibrio entre el principio representativo y el principio de participación directa, puesto que se exige que la consulta popular sea solicitad por los respectivos Alcaldes, previo acuerdo por mayoría absoluta del Pleno de la correspondiente Corporación Municipal; y de naturaleza material, consistente en admitir únicamente consultas relativas a asuntos que reúnan simultáneamente las notas de ser de la competencia propia municipal, de carácter local y de especial relevancia para los intereses de los vecinos, excluyéndose, en todo caso, loa asuntos relativos a la Hacienda Local. La apreciación de si el asunto es de indudable relevancia para los vecinos se considera la manifestación más directa de los requerimientos del aludido equilibrio entre el principio representativo y el de participación directa e incide en la concreción de los principios organizativos expresamente recogidos y articulados en la legislación de régimen local». 
la autorización encaja perfectamente en el marco del artículo 43.2 de la Ley $30 / 92$ referente a las solicitudes formulas por los interesados, y que por tanto las previsiones de la citada Ley $30 / 92$ sobre la falta de resolución expresa y el silencio administrativo son plenamente aplicables a la autorización prevista en el artículo 71 de la Ley Reguladora de Bases de Régimen local, lo que confirmaría su carácter de auténtico acto administrativo (82).

Hay que tener en cuenta que el artículo 71 de la LRBRL ha restringido tanto los requisitos para la celebración de la consulta popular y ha ceñido tanto los asuntos susceptibles de dar lugar a la misma a los intereses locales (asuntos de la competencia propia municipal y de carácter local que sean de especial relevancia para los intereses de los vecinos), que el mero control de legalidad es suficiente para garantizar que no van a quedar afectados intereses supralocales. Lo contrario podría suponer una restricción de la autonomía local.

\section{Convocatoria de la consulta y celebración de la misma}

Obtenida en su caso la autorización del Gobierno procede la convocatoria de la consulta. El artículo 71 de la Ley de Bases de Régimen Local parece atribuir la competencia para la convocatoria al Municipio a través de su Alcalde, si bien dicho precepto ha sido interpretado de manera desigual por las distintas normas autonómicas que regulan esta materia. La Ley andaluza sobre consultas populares 2/2001 de 3 de mayo observa en su articulo 11 este criterio y atribuye al Alcalde la convocatoria de la consulta en los tres días hábiles siguientes a la recepción de la comunicación del otorgamiento de la autorización. $Y$ en este mismo sentido se pronuncia la Ley Foral 27/2002 de 28 de octubre. Las Leyes 20/2006 de 15 de diciembre de régimen local de las Islas Baleares, 7/1999 de 9 de abril sobre Administración Local de Aragón, 1/2003 de 3 de marzo atribuyen la competencia a los Ayuntamientos aunque sin especificar el órgano concreto que debe proceder a la convocatoria.

Otras normas autonómicas han asignado la competencia para convocar la consulta a los órganos autonómicos, teniendo en cuenta que en tales casos los Municipios han de solicitar la autorización del Gobierno central por conducto de la Administración autonómica. Así se prevé por ejemplo en el Decreto Legislativo 2/2003 de 28 de abril por el que se aprueba el texto refundido de la Ley Municipal y de Régimen Local de Cataluña, según el procedimiento establecido en sus artículos 159 y 160 .Y asimismo se regula

(82) La consideración de la autorización del Gobierno como un acto administrativo se constataba igualmente en el proyecto de Real Decreto regulador del procedimiento de autorización por el Gobierno de la Nación de las consultas populares municipales, y que finalmente no llegó a aprobarse, que fijaba un plazo máximo de resolución de tres meses, entendiendo estimada la solicitud caso de que trascurriera dicho plazo sin resolución expresa. 
en la Ley 2/2003 de 11 de marzo de Administración Local de la Comunidad Autónoma de Madrid y en la Ley 5/97 de 22 de julio sobre Administración Local de la Comunidad Autónoma de Galicia que deberán efectuar la convocatoria mediante Decreto en el que se fijarán los términos exactos de la consulta, así como la fecha y lugar en que debe realizarse, Decreto al que deberá darse la preceptiva publicidad.

En mi opinión estas normas no se ajustan a la normativa básica estatal. Bien es cierto que el artículo 71 no alude expresamente a la necesidad de que sea el Alcalde quien haya de convocar la consulta, pero este es el sentido que debe darse a su contenido cuando señala que "los Alcaldes, previo acuerdo por mayoría absoluta del Pleno y autorización del gobierno de la nación podrán someter a consulta popular .... Es evidente que el precepto está haciendo referencia la intervención del Alcalde cuando la decisión sobre la celebración de la consulta ha obtenido el respaldo del Pleno y la autorización del Gobierno, de forma que no cabe otra actuación que su convocatoria.

El procedimiento de celebración de las consultas populares, presenta ciertas similitudes con los procedimientos electorales, y en este sentido algunas normas autonómicas remiten a la legislación de Régimen Electoral General, aunque con algunas peculiaridades. Así el artículo 11 de la Ley Foral 27/2002 de 28 de noviembre reguladora de las consultas populares de ámbito local. Por su parte, el artículo 161 del Decreto Legislativo 2/2003 de 28 de abril, por el que se aprueba el Texto Refundido de la Ley Municipal y de Régimen Local de Cataluña establece en su artículo 161 que la realización de las consultas populares ha de ajustare a los procedimientos establecidos por la legislación del Estado sobre referéndum, con determinadas peculiaridades que recoge este mismo precepto.

El hecho de que se prevea un cauce para el ejercicio de las consultas similar al previsto en la legislación electoral, así como la vinculación de la participación con el derecho de sufragio activo que efectúan algunas normas autonómicas ha sido precisamente la causa de que en ocasiones se haya confundido la verdadera naturaleza jurídica de dichas consultas considerándolas una modalidad de referéndum específico del ámbito local, con todas las consecuencias que ello supone, entre otras su consideración como un derecho fundamental amparado en el artículo 23 de la Constitución.

Ahora bien, hay que tener en cuenta que únicamente cabe hablar de procedimientos electorales cuando en ellos se dilucidan cuestiones políticas, es decir cuando el cuerpo electoral está llamado a ejercer el poder político (83). Sin embargo las consultas populares son una modalidad de

(83) Así por ejemplo se deduce de la STC de 11 de septiembre de 2008 que al aludir al procedimiento electoral entiende que es aquel basado en el censo, gestionado por la Administración electoral y asegurado con garantías jurisdiccionales específicas, siempre en relación con los asuntos públicos cuya gestión, directa o indirecta, mediante el ejercicio del poder político por parte de los ciudadanos constituye el objeto del derecho fundamental reconocido por la Constitución en el artículo 23. 
participación administrativa y no política, razón por la cual el procedimiento para su celebración no puede considerarse con propiedad como un procedimiento electoral, a pesar de las similitudes apuntadas con el mismo y de la remisión efectuada por algunas normas de origen autonómico.

Cuando las normas autonómicas regulan la celebración de las consultas populares pretenden establecer procedimientos que garanticen el derecho de participación de todos los sujetos convocados (84) así como la transparencia de la consulta y del resultado obtenido (85), razón por la cual se remiten en ocasiones a las normas que regulan los procedimientos electorales, en la medida en que contienen un conjunto de garantías ineludibles para considerar a las consultas populares como una forma cualificada de participación administrativa, encauzada a través de un procedimiento democrático de participación y representativa de la opinión general.

No olvidemos que existen otros cauces para conocer la opinión de los vecinos tales como los sondeos, foros, encuestas de opinión etc., pero ninguno de ellos se encuentra revestido de las garantías y formalidades necesarias para considerarlo exponente de la opinión general expresada democráticamente. Del mismo modo, los trámites establecidos en el contexto de un procedimiento administrativo, como la información pública son también una forma de participación funcional en la actividad administrativa, basada en el principio de democracia participativa, pero tampoco pueden ser considerados como exponentes de la opinión general.

Para ello es necesario establecer un procedimiento que garantice la participación de todos los sujetos convocados dotado de las garantías necesarias y cuyo resultado sí pueda ser significativo de la opinión general. Es precisamente este procedimiento el que permite distinguir las consultas populares de otras modalidades de participación no formalizadas, ni expresivas de la opinión general a las que nos hemos referido antes.

En cambio la vinculación de la participación en la consulta al derecho de sufragio activo no es relevante para su calificación como mecanismo formalizado y cualificado de la democracia participativa. Recordemos que no se trata de una participación política, sino administrativa, razón por la cual hemos considerado injustificada la restricción efectuada por algunas normas autonómicas que supeditan el derecho de participación en las

(84) SÁNCHEZ MORÓN, M., ha puesto de manifiesto la relación existente entre el derecho de participación y el principio de igualdad que impide privilegiar la participación de ciertos grupos o categorías sociales cuando no existan motivos para ello. "El principio de participación en la Constitución española», REDA N. ${ }^{\circ} 89,1979$, Pág. 2000.

(85) Como manifestación de esas garantías el Decreto Foral 128/2005 de 17 de octubre por el que se aprueban los modelos de papeletas, sobres de votación, actas de constitución y actas de escrutinio que han de servir, con carácter general, para las consultas populares de ámbito local que se convoquen en la Comunidad Foral de Navarra. 
consultas a la titularidad del derecho de sufragio activo en las elecciones municipales.

\section{Los efectos de la consulta popular}

En su configuración legislativa las consultas populares de ámbito local se caracterizan por su carácter facultativo y no vinculante, de forma que sus efectos son meramente consultivos. La literalidad del artículo 71 de la Ley de Bases de Régimen Local permite descartar de plano la obligatoriedad de la consulta municipal, de forma que el precepto pone de manifiesto la ausencia de previsión legal que imponga con carácter preceptivo la celebración de la consulta con carácter previo a la adopción de una decisión (86).

De esta forma las consultas populares no son un cauce de participación funcional ineludible para la perfección jurídica del acto sometido al mismo, pero supuesto el hecho de su celebración, cabe preguntarse cual es el alcance de sus efectos en las resoluciones administrativas que se adopten.

En este sentido es necesario tomar en consideración la naturaleza jurídica de las mismas, teniendo en cuenta que constituyen una manifestación de la democracia participativa, con lo que se insertan en el marco de una función o actividad de naturaleza administrativa, de forma que la consulta popular no constituye una manifestación de soberanía popular que vincule a los poderes públicos, sino la expresión de una opinión o parecer que implica la colaboración de los ciudadanos con los poderes públicos, pero sin sustituir en ningún momento la capacidad de decisión de los órganos competentes, sino simplemente como un complemento de su actuación.

Por otra parte la ausencia de mención expresa de la Constitución a las consultas populares en el ámbito local y la primacía otorgada por la misma a los mecanismos de la democracia representativa deben llevar a la conclusión de interpretar restrictivamente los efectos de las mismas. El resultado de la consulta efectuada debe ser tenido en cuenta y ponderado por los órganos encargados de decidir pero con efectos limitados, constituyendo un elemento más de juicio para la formación de la voluntad de los órganos administrativos pero sin efecto vinculante (87). Hablamos naturalmen-

(86) Vid FONT I LLOVET, T., «El referéndum local en España», obra cit., Pág. 125.

(87) Indica la STC de 11 de septiembre de 2008 que el referéndum no se define precisamente por su carácter vinculante que podrá o no darse en función de la modalidad ante la que nos encontremos. Señala la citada sentencia que "La circunstancia de que no sea jurídicamente vinculante resulta de todo punto irrelevante, pues es obvio que el referéndum no se define frente a otras consultas populares por el carácter vinculante de su resultadon: 
te desde un punto de vista jurídico, porque desde un punto de vista político la realidad es que resulta muy difícil de imaginar que los órganos de gobierno se aparten del criterio popular manifestado en la consulta, siendo ésta expresiva de la opinión general sobre un asunto de especial relevancia.

Igualmente desde un punto de vista constitucional, el artículo 140 atribuye el gobierno de los municipios a los Ayuntamientos a través de sus órganos de gestión. Ello debe ser puesto en relación con el artículo 69.2 de la Ley de Bases de Régimen Local, según el cual las formas, medios y procedimientos de participación que las Corporaciones locales establezcan en ejercicio de su potestad de organización no podrán menoscabar las facultades de decisión que corresponden a los órganos representativos del municipio, de forma que su eficacia normativa adquiere carácter meramente consultivo (88).

Es cierto que este mismo carácter facultativo y no vinculante puede predicarse también de otros instrumentos a través de los cuales la Administración puede conocer la opinión de los vecinos sobre un determinado asunto. Así por ejemplo las encuestas o los sondeos de opinión, audiencias públicas, foros de consulta, paneles y jurados ciudadanos (89). No obstante, estos instrumentos no implican la participación de todos los vecinos, ni siguiera de aquellos que cuenta con el derecho de sufragio activo, sino sólo de un grupo representativo de los mismos, en ocasiones elegidos discrecionalmente por la propia Administración, donde además la ausencia de un procedimiento formalizado para articular dicha participación, no permite asegurar que estas opiniones sean representativas de la opinión general. Se trata en muchos casos de mecanismos de participación que encuentran su ámbito más adecuado de aplicación en asuntos ordinarios o de gestión y con los que la Administración pretender valorar el resultado de una actuación concreta y el grado de satisfacción de los administrados en la prestación de un servicio. Por otra parte no garantizan ni expresan la opinión de todos los vecinos, sino sólo la de algunos de ellos, por lo que resultan insuficientes en aquellas materias de especial relevancia, en las que resulta conveniente conocer la opinión general a través de un procedimiento formal basado en los principios de sufragio universal, libre, igual, directo y secreto y con las debidas garantías de participación.

(88) Es cierto que el contenido de este artículo puede ser interpretado en el sentido de incluir en esta limitación únicamente las formas de participación previstas por el municipio en sus ordenanzas, y no las consultas populares que son objeto de una consideración expresa por la Ley de Bases de Régimen Local.

(89) Ver Ley 11/2008, de 3 de julio de 2008 de la Generalitat, de Participación ciudadana en la Comunidad Valenciana, cuyos artículos 17 y siguientes establecen una enumeración de los instrumentos de participación ciudadana. 
Por estas mismas razones las posibilidades que ofrece el trámite de información pública resultan insuficientes en estas ocasiones. Con las consultas populares se trata de conocer la opinión de los vecinos en un determinado asunto que por su trascendencia supera las posibilidades que ofrece el trámite de información pública.

El efecto de la consulta popular es obligar al órgano competente a valorar en un plazo razonable los resultados de la misma. A partir de los resultados de la consulta se someterá al pleno o al órgano competente para resolver la propuesta o proyecto presentado para que a la vista de los mismos adopte la decisión más acertada. La Ley del Parlamento de Navarra prevé en su artículo 26.4 esta conclusión, señalando al mismo tiempo que dicha deliberación habrá de producirse en el mes siguiente a la publicación en el Boletín Oficial de Navarra del resultado de la consulta popular.

Cabe plantearse si una vez celebrada la consulta a iniciativa popular por la vía del artículo 70 bis de la LRBRL debe retomarse el procedimiento previsto en este artículo, es decir valoración por el pleno y sometimiento de la propuesta o proyecto presentado al órgano competente para resolver. En mi opinión la celebración y resultado de la consulta dispensa del cumplimiento de los trámites previstos en el citado de forma que el acuerdo o decisión podrá ser adoptado directamente por el órgano competente, pues en este caso la opinión de los vecinos sustituye al debate y votación de su órgano de representación que prevé el artículo 70 bis. 
LABURPENA: Herri-galdeketak demokrazia partehartzailearen adierazgarrietako bat dira. Legeak onartuta dauzka tokiko administrazioen esparruan, eta horren bitartez, udalerrietako biztanleek aukera daukate beren eskumeneko herriko gai garrantzitsuei buruz beren iritzia emateko. Ez dira, ordea, herriaren burujabetasunaren adierazpen, eta ez dute gauzatzen inongo botere politikorik; alderantziz, herritarrek administrazioarekin elkarlanean aritzea behar duen izaera administratiboko betebehar edo zeregin baten baitan doaz. Gainera, kontsulta herritarrek berek planteatu badute, orduantxe hartzen du mailarik gorena administrazioaren jardueratako parte-hartze demokratikoaren printzipioak.

Lan honetan, udalerritako herri-kontsulten benetako izaera juridikoa aztertzen du, irailaren 11 an Epaitegi Konstituzionalak emandako ebazpena (103/2008) kontuan hartuta, ekainaren 27an Eusko Legebiltzarrak emandako 9/2008 legea konstituzioaren aurkakoa ote zen aztertzen duena, lege horrek kontsulta bidezko erreferendumaren erregimen juridikoa zehaztu baitu, eta bestelako parte-hartze formetatik bereizi, besteak beste, herri-kontsultetatik.

HITZ GAKOAK: Parte-hartzeko demokrazia. Zuzeneko demokrazia. Erreferenduma. Herri-kontsultak. Herri-ekimena.

RESUMEN: Las consultas populares son una forma de democracia participativa, que alcanza reconocimiento legislativo en el ámbito de la Administración local, y a través de las cuales los vecinos de un municipio pueden expresar su opinión sobre asuntos relevantes de la competencia local. No constituyen una manifestación de soberanía popular, ni implican el ejercicio de poder político, sino que se insertan en el marco de una función o actividad de naturaleza administrativa que implica la colaboración de los ciudadanos con la Administración. Cuando además se plantean a iniciativa de los vecinos el principio de participación democrática en la actividad administrativa alcanza su máxima expresión.

En este trabajo se analiza la verdadera naturaleza jurídica de las consultas populares locales teniendo en cuenta la STC 103/2008 de 11 de septiembre, relativa a la inconstitucionalidad de la Ley del Parlamento Vasco 9/2008, de 27 de junio, que ha perfilado el régimen jurídico del referéndum consultivo, diferenciándolo de otras formas de participación, entre ellas las consultas populares.

PALABRAS CLAVE: Democracia participativa. Democracia directa. Referéndum. Consultas populares. Iniciativa popular.

ABSTRACT: Popular plebiscites are a participatory democracy form which is legally acknowledged in the field of Local Entities and by means of whom the residents of municipalities can voice their opinions about relevant issues regarding the local powers. They are not a sign of popular sovereignty and they do not imply the exercise of political power but they are in the frame of an administrative function or activity that entails the collaboration among citizens and Administration. When plebiscites are proposed by the residents of a municipality the principle of democratic participation within the administrative action reaches its highest expression.

In this work, the true legal nature of this local popular plebiscites is analyzed taking into account the judgment delivered by the Constitutional Court (STC 103/2008, 
June 27), which shaped the legal regime for consultative referendums differentiating between other forms of participation, among them, popular plebiscites.

KEY WORDS: Participatory democracy. Direct democracy. Referendum. Popular plebiscites. Popular initiative. 